\title{
Obtaining Ionospheric Conditions according to Data of Navigation Satellites
}

\author{
Olga Maltseva and Natalia Mozhaeva \\ Institute for Physics, Southern Federal University, St. Stachki 194, Rostov-on-Don 344090, Russia \\ Correspondence should be addressed to Olga Maltseva; mal@ip.rsu.ru
}

Received 8 March 2015; Accepted 19 May 2015

Academic Editor: Francesco D’Agostino

Copyright ( 2015 O. Maltseva and N. Mozhaeva. This is an open access article distributed under the Creative Commons Attribution License, which permits unrestricted use, distribution, and reproduction in any medium, provided the original work is properly cited.

\begin{abstract}
Defining ionospheric conditions, the deviation of the observational value of the total electron content TEC(obs), measured by means of navigation satellites, from a median is a bench mark. According to more than 40 ionospheric stations during April 2014 it is shown that synchronism of change of deviations of TEC and critical frequency foF2 of the ionosphere is kept under quiet and moderate disturbed conditions. This fact allows to use a median of the equivalent slab thickness $\tau(\mathrm{med})$ as a reliable calibration factor to calculate foF 2 from TEC(obs). The efficiency coefficient of joint use of $\tau$ (med) and TEC(obs) changes from 1.5 to 4 with average value 2.2 across the globe. The highest coefficient corresponds to middle latitudes, however the estimations obtained for high- and low-latitude areas indicate possibility to use $\tau$ (med) and TEC(obs) in these areas.
\end{abstract}

\section{Introduction}

The total electron content TEC, measured by such navigation satellite systems as GPS, GLONASS, GALILEO, and others becomes a key parameter in ionospheric condition estimation [1], as (1) TEC continuous global monitoring, (2) TEC data availability on the Internet, (3) presence of the information about $\mathrm{N}(\mathrm{h})$-profile of the ionosphere. Areas of its usage are very wide: from development of an index of the ionospheric disturbances (e.g. [2]) to estimation of errors in coordinate measurement in remote sensing (e.g. [3]). TEC allows observing such phenomena as daytime TEC maxima, nighttime TEC peaks, summer TEC value decreases, and spring and fall TEC maxima (e.g. [4]). In view of importance of this parameter, the great attention is given to increase of accuracy of its determination (e.g. $[5,6])$. More exact determination of the ionospheric parameters is returned for more exact navigation decision (e.g. [7]). However from the point of view of radio propagation in the ionosphere the most important parameter is a critical frequency foF 2 . This frequency directly defines a maximum usable frequency MUF through MUF = $M(D) *$ foF2, where $M(D)$ is a propagation factor at the path with length $D$. Modeling of this particular parameter is very important for HF communication. In [8] it is proposed to build maps of foF2 for ionospheric support of HF radio communication using maps of TEC. The model [9] which was extended now as the IRI-Plas model [10] was used; however verification of method has been fulfilled on an example of only several days and authors have noted that their approach needs verification on larger volume of the data and in various geo-heliophysical conditions. In the present paper, we consider the use of TEC to calculate foF2. There are a number of assimilation methods of using slant TEC [11-13] but directly foF 2 value is not calculated in these methods. Such calculation involves the use of a proportionality coefficient between TEC and NmF2, namely, the equivalent slab thickness of the ionosphere $\tau=\mathrm{TEC} / \mathrm{NmF}$. Traditionally, values of $\tau$ were calculated by the International reference model IRI [14], that is $\tau$ (IRI) $=$ TEC(IRI)/NmF2(IRI). These values were used for calculation of foF 2 by means of the observational values TEC(obs) under the formulas $\mathrm{NmF} 2=$ TEC (obs) $/ \tau$ (IRI), $((\mathrm{foF} 2), \mathrm{Hz})^{2}=8.07_{10} 7 \mathrm{NmF} 2, \mathrm{sm}^{-3}[15-$ 17]. Authors of the paper [18] have proposed using the observational median $\tau($ med $)=\operatorname{med}(\mathrm{TEC}(\mathrm{obs}) / \mathrm{NmF} 2(\mathrm{obs})$ ) together with TEC(obs) and showed that this use allows to get foF 2 which are closer to experimental values than foF2 for $\tau$ (IRI) because of the large difference between $\tau$ (med) and $\tau$ (IRI). An important application is also the filling of 
gaps of experimental data of foF2. In [19] an attempt is done to use experimental information concerning $\tau$ to determine foF2 from the TEC, in particular, the optimal constant $\tau$ and the expression of foF $2=K \sqrt{ }$ TEC with a constant $K$ were introduced. However in [20] it is shown that results of such approach are worse than for $\tau$ (med). The most comprehensive research was performed in [21].

In the present work, we show efficiency of $\tau$ (med) usage through the example of the data of individual ionospheric stations in various regions of the globe. In 2013-2014, there was data of many additional stations. This allows to estimate efficiency of usage of $\tau$ (med) on a global scale. In the present paper the data of 44 stations in various regions are used. For the majority of these stations efficiency of $\tau$ (med) use has not previously been investigated. Because of the greatest interest which is caused by a situation during disturbance, April 2014 is selected. This month has the biggest recent disturbance that is characterized by minimum Dst $=-80 \mathrm{nT}$.

Section 2 describes observational data. Section 3 illustrates efficiency of use of $\tau$ (med) together with TEC for individual stations in high-latitude and equatorial zones in comparison with results of middle-latitude stations which are considered as the standard. The estimation on a global scale is given in Section 4. Possibility of creating or using of a global model of $\tau$ (med) is discussed in Section 5.

\section{Observational Data}

Data of the critical frequency foF2 was taken from SPIDR data base (http://spidr.ngdc.noaa.gov/spidr/index.jsp). Coordinates of some stations are as follows: Juliusruh $\left(54.6^{\circ} \mathrm{N}\right.$, $\left.13.38^{\circ} \mathrm{E}\right)$, Goosebay $\left(53.3^{\circ} \mathrm{N}, 60.4^{\circ} \mathrm{W}\right)$, Thule $\left(77.5^{\circ} \mathrm{N}, 69.2^{\circ} \mathrm{W}\right)$, Grahamstown $\left(33.3^{\circ} \mathrm{S}, 26.5^{\circ} \mathrm{E}\right)$, and Ascension Island $\left(7.9^{\circ} \mathrm{S}\right.$, $\left.14.4^{\circ} \mathrm{W}\right)$. Data of foF2 are frequently absent or have erroneous values because of automatic scaling (e.g., [22, 23]). Values of TEC for five global maps JPL, CODE, UPC, ESA, and IGS were calculated using IONEX files (ftp://cddis.gsfc.nasa.gov/ pub/gps/products/ionex/) for all stations and time periods. TEC is the total number of electrons within a $1-\mathrm{m}^{2}$ column along a path through the ionosphere. TEC is measured in TEC Units (TECU), where 1TECU $=10^{16}$ electrons $/ \mathrm{m}^{2}$. Results of papers $[18,20]$ showed that in most cases the best correspondence with experimental foF 2 values is provided by $\tau(\mathrm{JPL})$ for map JPL; however there can be separate regions or time periods when another map provides the best conformity with experimental data.

\section{Efficiency of $\tau$ (med) Use for Individual Stations}

As it was mentioned in the introduction, traditional procedure of obtaining foF2 from the observational values TEC(obs) consists in use of model $\tau($ IRI). The big deviations of the calculated values of foF 2 for the IRI model from foF2(obs) are connected with deviation of $\tau$ (IRI) from a median $\tau$ (obs). These differences are illustrated in Figures 1(a)-1(e) for stations with various latitudes for July and December. Results are given for those years when data were available. Diurnal dependences of a median $\tau$ (obs) are presented in the left part of figures and $\tau($ IRI) is presented in the right part.

In July and December, differences between $\tau($ IRI) and $\tau$ (obs) are great; there is a certain dependence on a solar activity (on this time period, a solar activity decreases with increasing years). In December, values in a diurnal course are characterized by permanence at midday and maxima at hours of sunrises and sunsets. Model curves do not fully reflect these features. For several years the data foF 2 was absent. In this case usage of $\tau$ (med) for neighboring year can yield the better results than $\tau($ IRI). Figure $1(\mathrm{~b})$ gives the same results for the middle-latitude station Goosebay of the American region of northern hemisphere.

There is not a strong similarity between behavior of $\tau$ for two middle-latitude stations, though the common characteristics are seen like dependence on a solar activity, daytime permanence, and sunrise-sunset maxima of December values. Figure 1(c) shows results for the high-latitude station Thule of northern hemisphere.

Unlike middle-latitude stations both parameters $\tau$ (obs) and $\tau$ (IRI) have: (1) much bigger permanence in a diurnal course, (2) proximity of model and experimental values for years of the moderate to low activity, (3) the large variations with level of a solar activity. It can be illustrated by values not shown in Figures: for July of years of high solar activity 1999, 2000, and 2001 values $\tau$ (obs) were close to 600,650 , and $500 \mathrm{~km}$, and values of $\tau($ IRI) amounted to 690, 1060, and $910 \mathrm{~km}$. Figure 1(d) shows dependences of the low-latitude station Grahamstown of southern hemisphere.

It is evident that both parameters $\tau$ (obs) and $\tau$ (IRI) experience the least variations with level of solar activity in comparison with all other stations. Behavior patterns are similar to patterns of middle-latitude stations shifted by six months due to a difference in seasons. In December, many data of foF2 were absent. Because of the proximity $\tau$ (obs) for many years, missed values can be recovered using existing $\tau$ (obs) for other years. The situation for the equatorial station Ascension Island of southern hemisphere is shown in Figure 1(e).

Pictures in July and December are more similar. The behavior at a very high solar activity is out from a common picture.

Efficiency of $\tau$ (med) was estimated using absolute relative deviations $\mid \Delta$ foF $2 \mid$ of the calculated foF2 values from the experimental ones and relative standard deviations (SD) $\sigma$ (foF2). The IRI model, like any other empirical model, provides only median ionospheric parameters, that is, averages. To assess the accuracy of the determination of the parameters its results should be compared with the experimental medians. Such estimates, maybe not having the direct relation to article purpose, are useful to be done for high-latitude and low-latitude areas because they are much less than for middle-latitude regions. Results for middle-latitude regions serve as the etalon. However model values are often used for prediction of values of parameters in each individual day, that is, the instantaneous values. In this case, the differences between the observational (instantaneous) and model values will be higher and they characterize variations from day to 

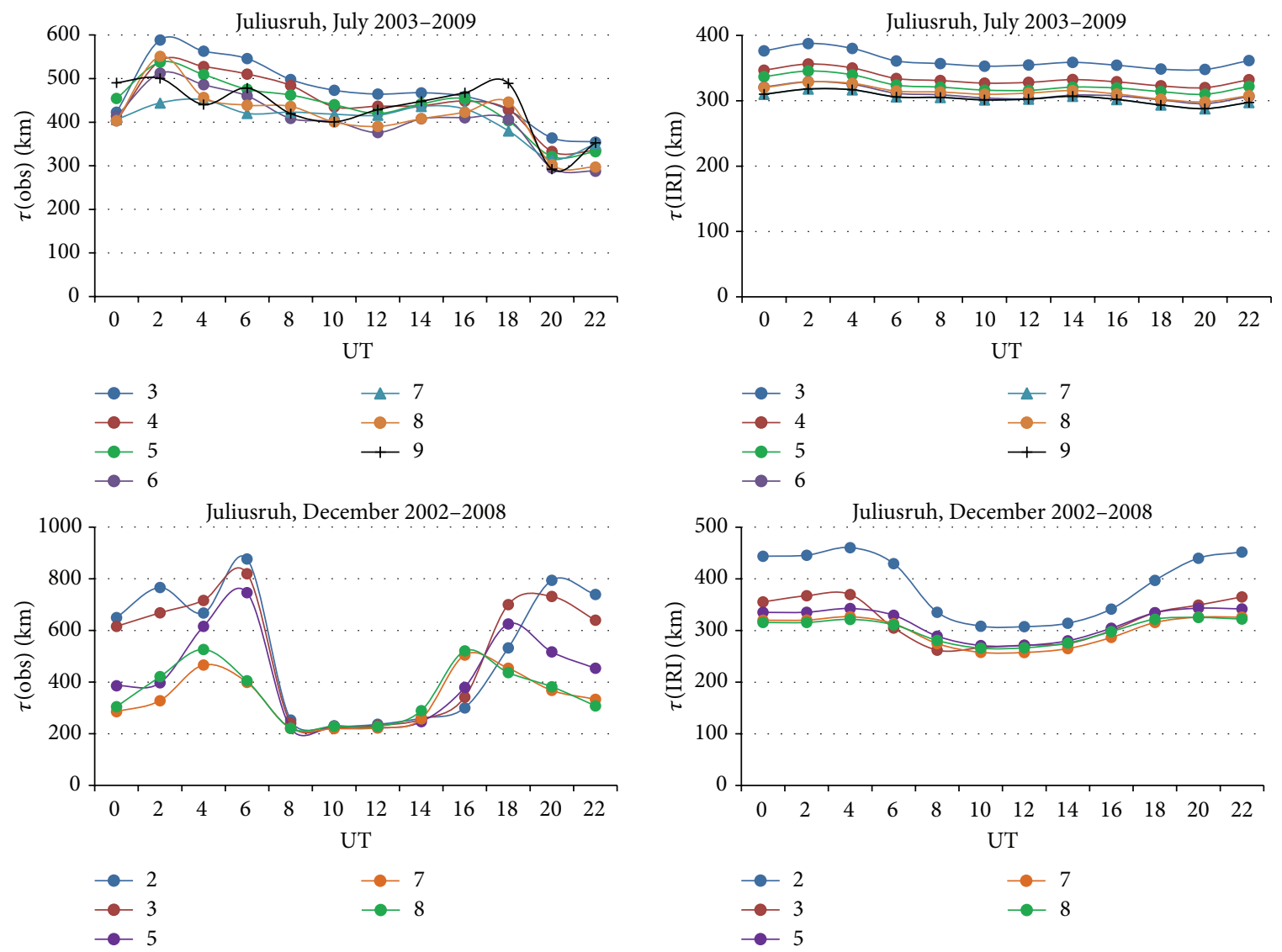

(a)
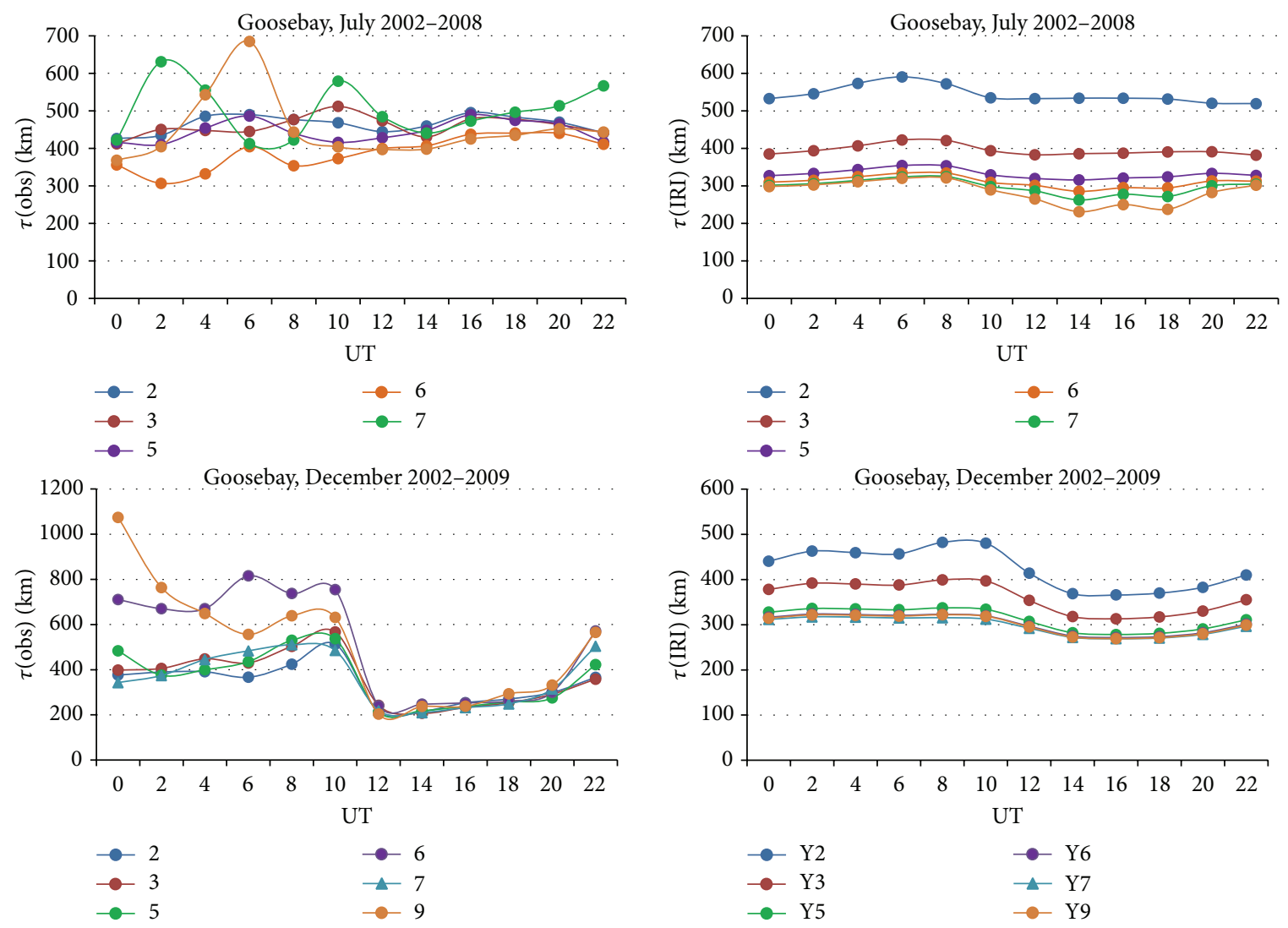

(b)

FIGURE 1: Continued. 

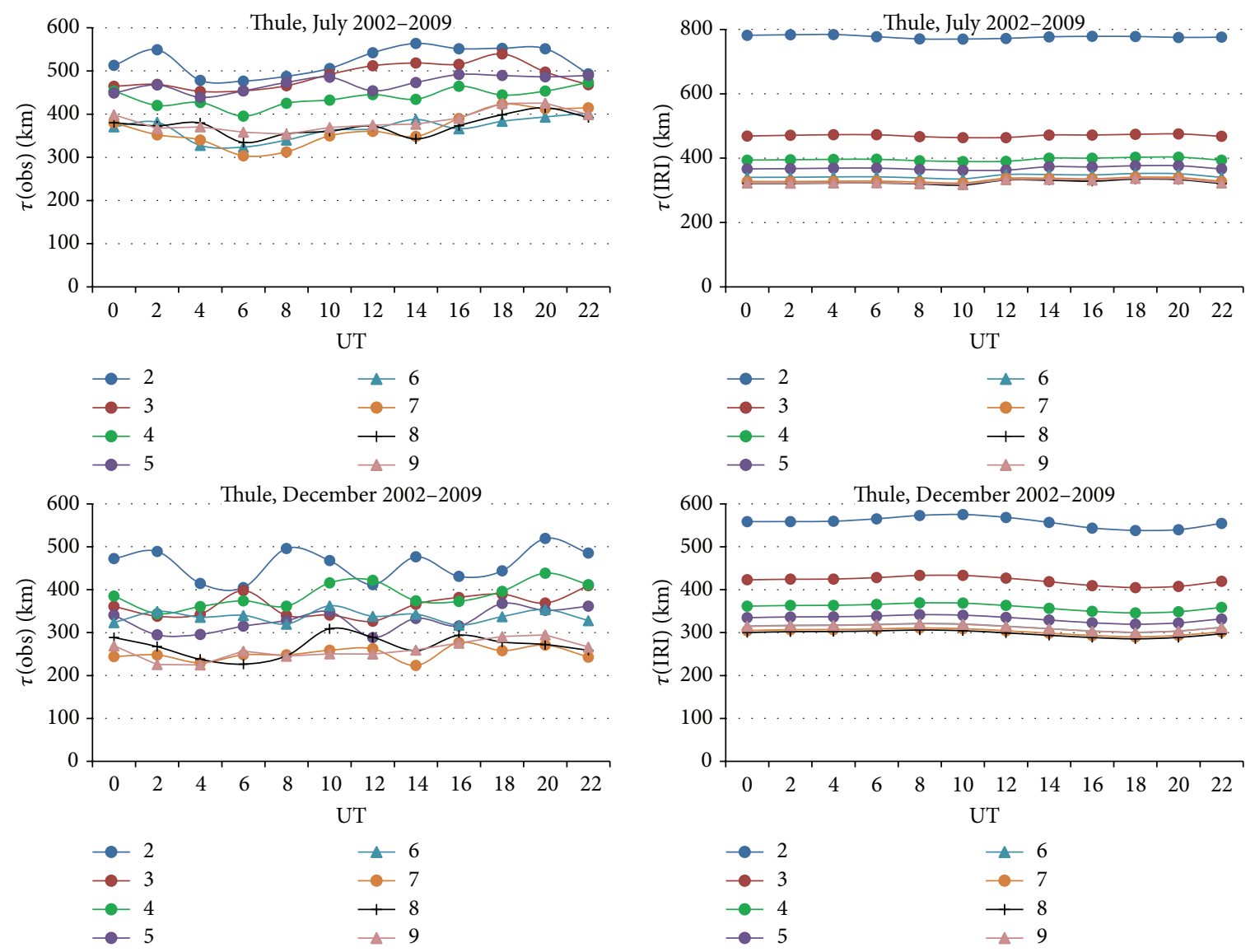

(c)
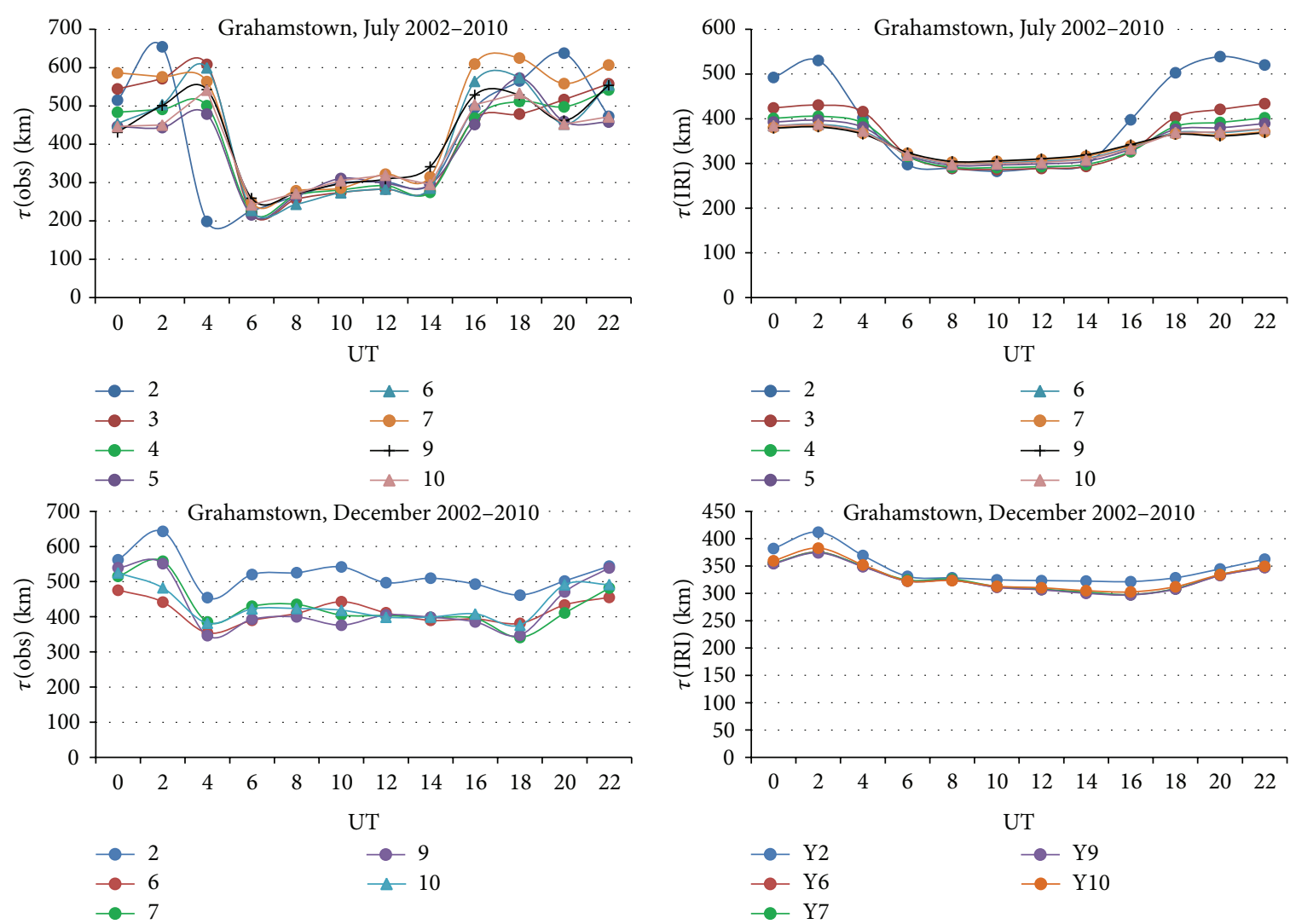

(d)

FIgUre 1: Continued. 

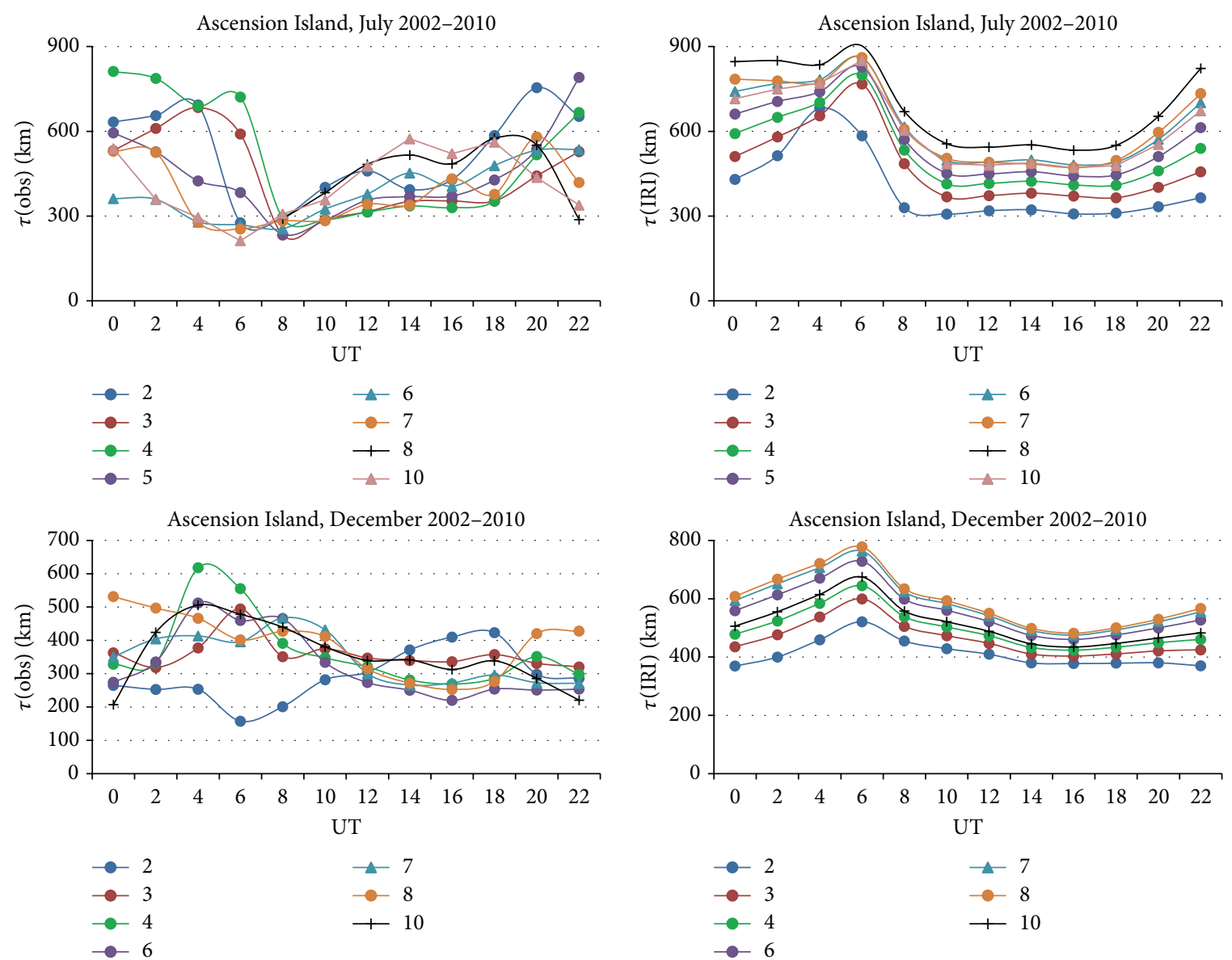

(e)

Figure 1: (a) Differences between model and experimental values of equivalent slab thicknesses for the middle-latitude station Juliusruh of the European region. (b) Differences between model and experimental values of equivalent slab thicknesses for the middle-latitude station Goosebay of the American region. (c) Differences between model and experimental values of equivalent slab thicknesses for the high-latitude station Thule. (d) Differences of model and experimental values of equivalent slab thicknesses for the low-latitude station Grahamstown. (e) Differences of model and experimental values of equivalent slab thicknesses for the equatorial station Ascension Island.

day. In assessing the accuracy the statistical characteristics of the medians are calculated to 24 or 12 (for the TEC to two hours increments). In evaluating the description of the instantaneous values an average over all days of the month is calculated. The advantage of $\tau$ (med) is that it allows to calculate (reconstruct) the instantaneous values foF 2 for each day and hour for the respective TEC(obs). The difference between the experimental and these reconstructed values characterizes the efficiency of $\tau$ (med) compared with the IRI model. Thus, three sets of deviations are compared in Figures 2(a)-2(e), that is, the average differences for (1) the median (blue dots), (2) model variations from day to day (black dots), and (3) reconstruction using $\tau$ (med) values (red dots).

Absolute deviations decrease with decreasing solar activity. The relative deviations have no such tendency as values of foF2 are decreased. Results for 2007-2009 stood out. Characteristically, the large deviations are obtained for the median. This is due to the extremely unusual period of low solar activity, for example, $[24,25]$. In [26] it is shown that, in these conditions, results of the IRI model worsen. In [27] the behavior of such characteristics, as foF2, hmF2, TEC, M3000F2, and MUF3000F2, in July and December 20012009, is investigated according to the Athens station. It is shown that the correspondence between the observational and IRI model parameters may be worse than during moderate or high activity periods. Nevertheless, results of use of $\tau$ (med) and TEC(obs) were not strongly changed. Results have been confirmed by comparison of MUF medians for four months of 2009 on the path Cyprus-Rostov.

Figures 2(b)-2(e) show results for the rest of stations used. Table 1 shows the statistical data containing coefficient $K$ and standard deviations for used options. Coefficient $K$ is the relation of absolute deviations for the model to deviations for usage of $\tau$ (med). This coefficient characterizes efficiency of joint use of $\tau$ (med) and TEC(obs) compared with the IRI model.

It is evident that everywhere $\tau$ (med) provides the better results than the IRI model. The efficiency ratio $K_{\text {eff }}$ for all stations is close to 2 . This conclusion concerns variations of day to day. When we compare medians during a low 

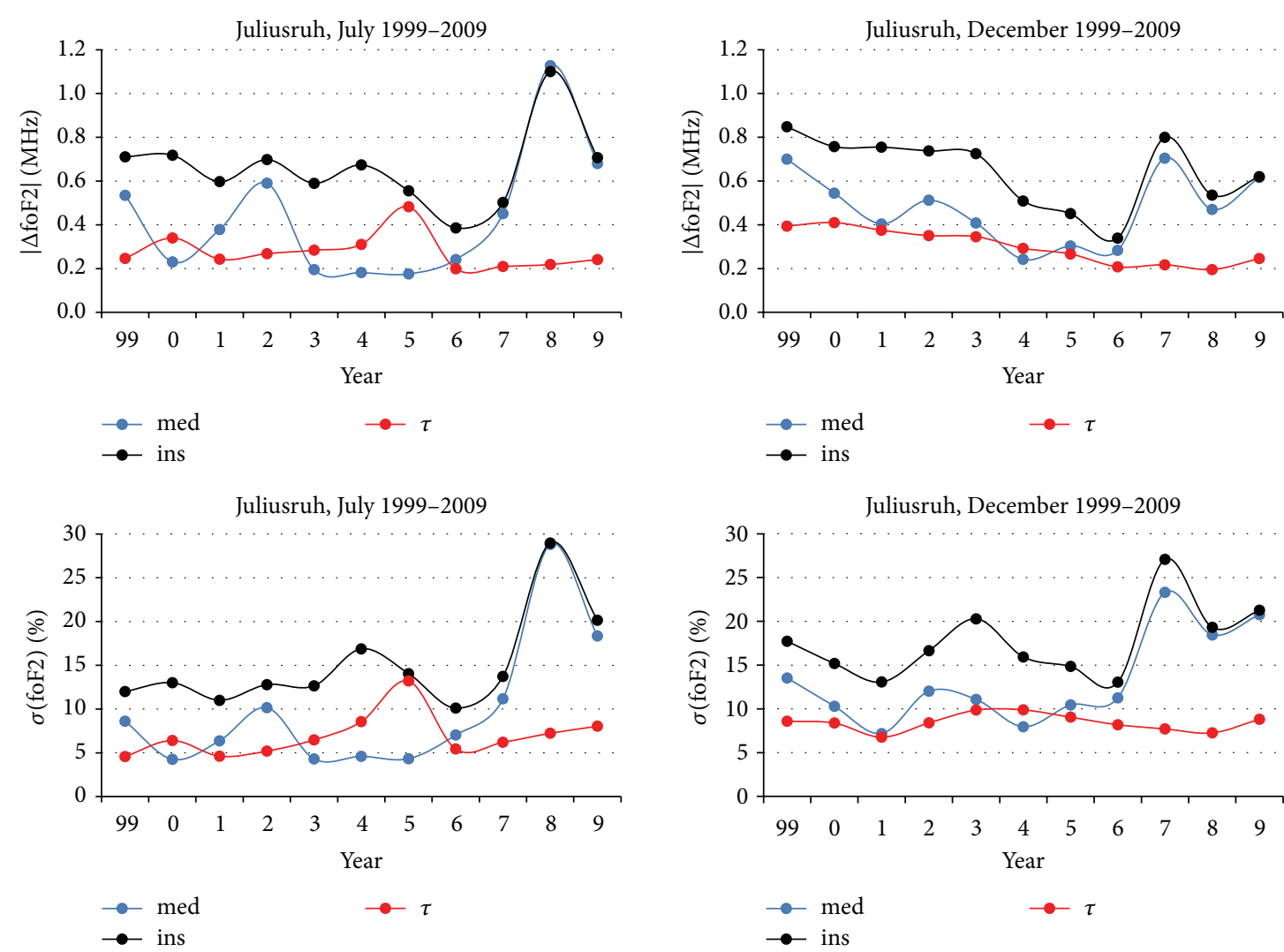

(a)
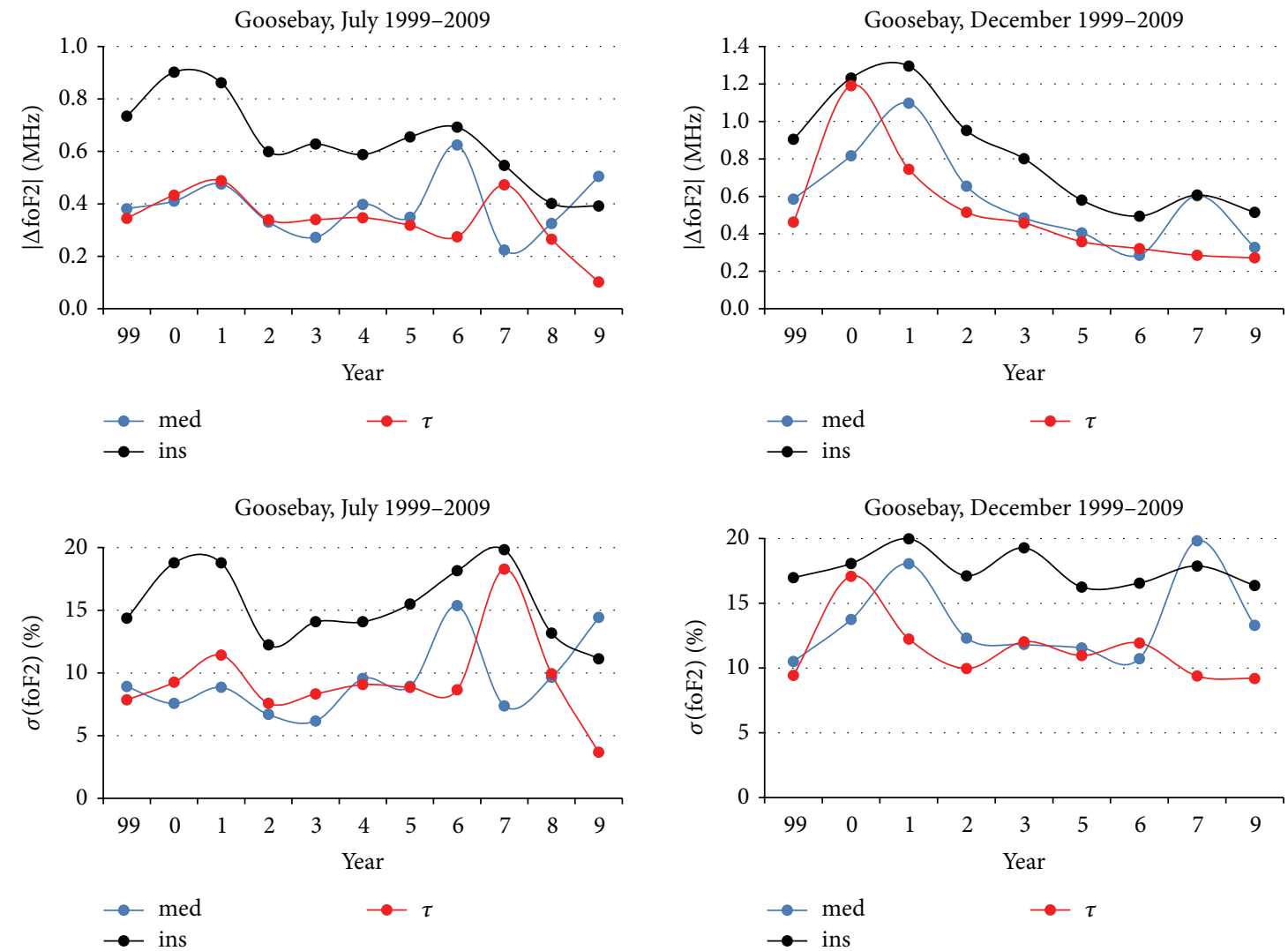

(b)

Figure 2: Continued. 

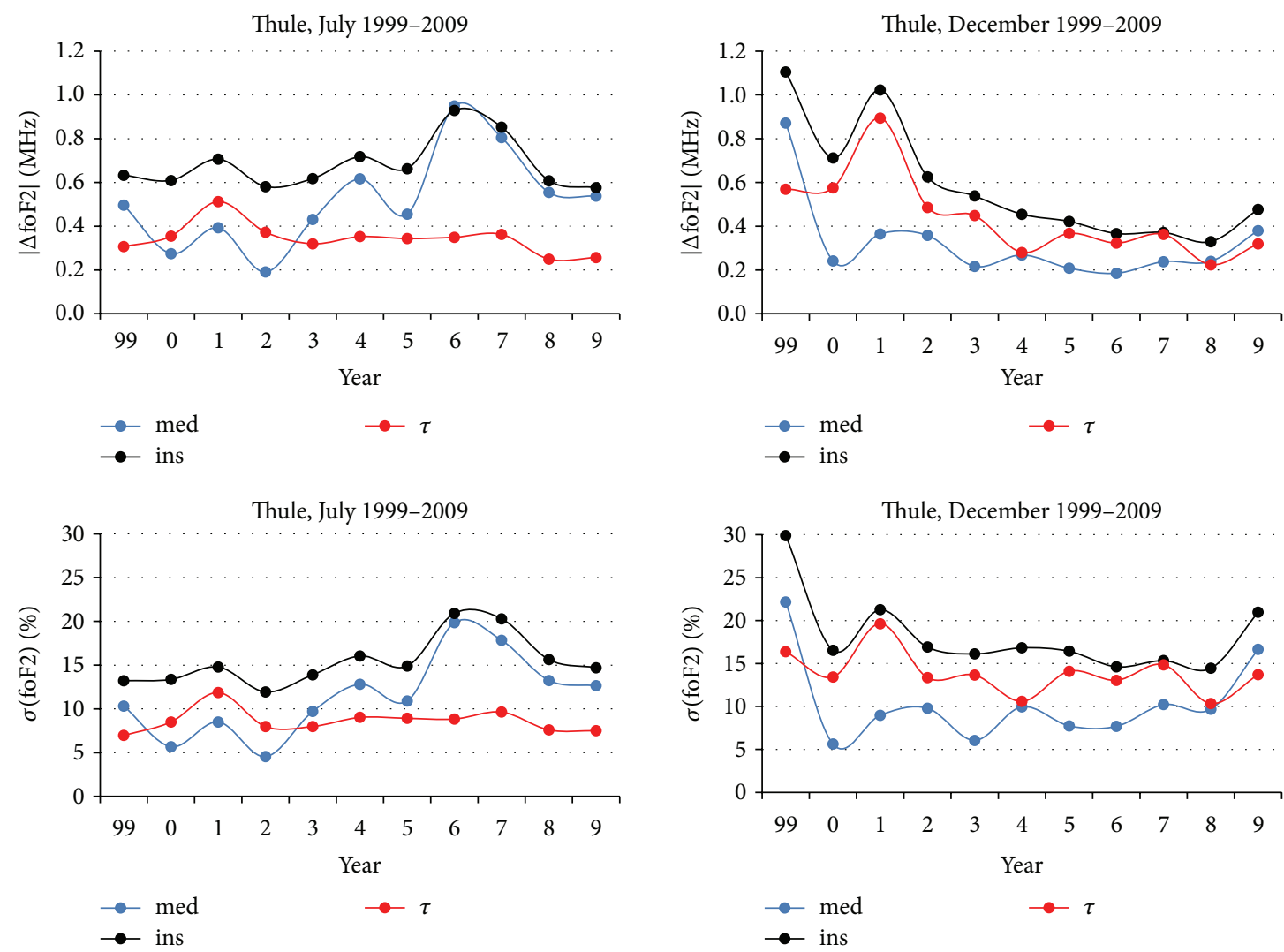

(c)
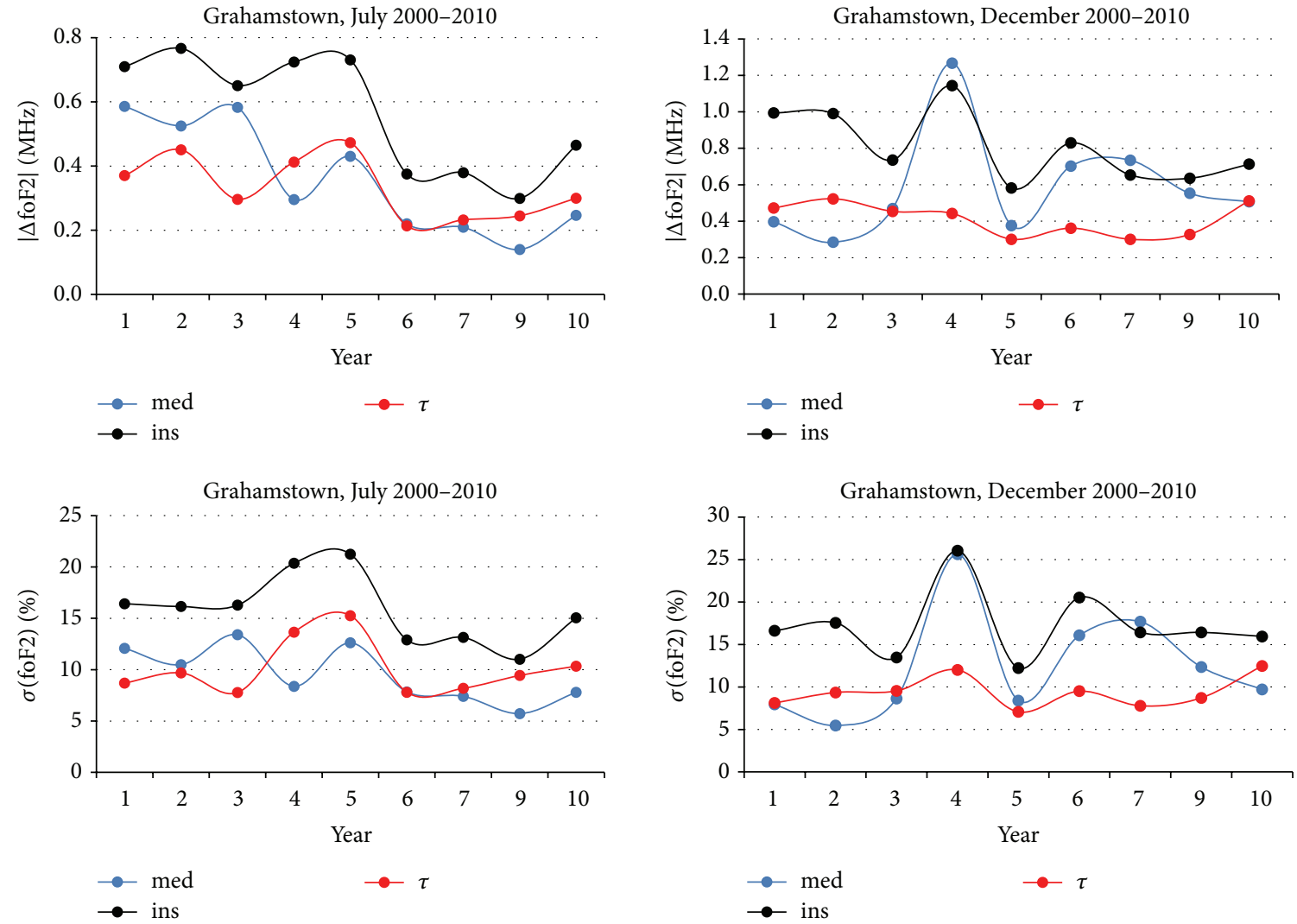

(d)

FIgURe 2: Continued. 

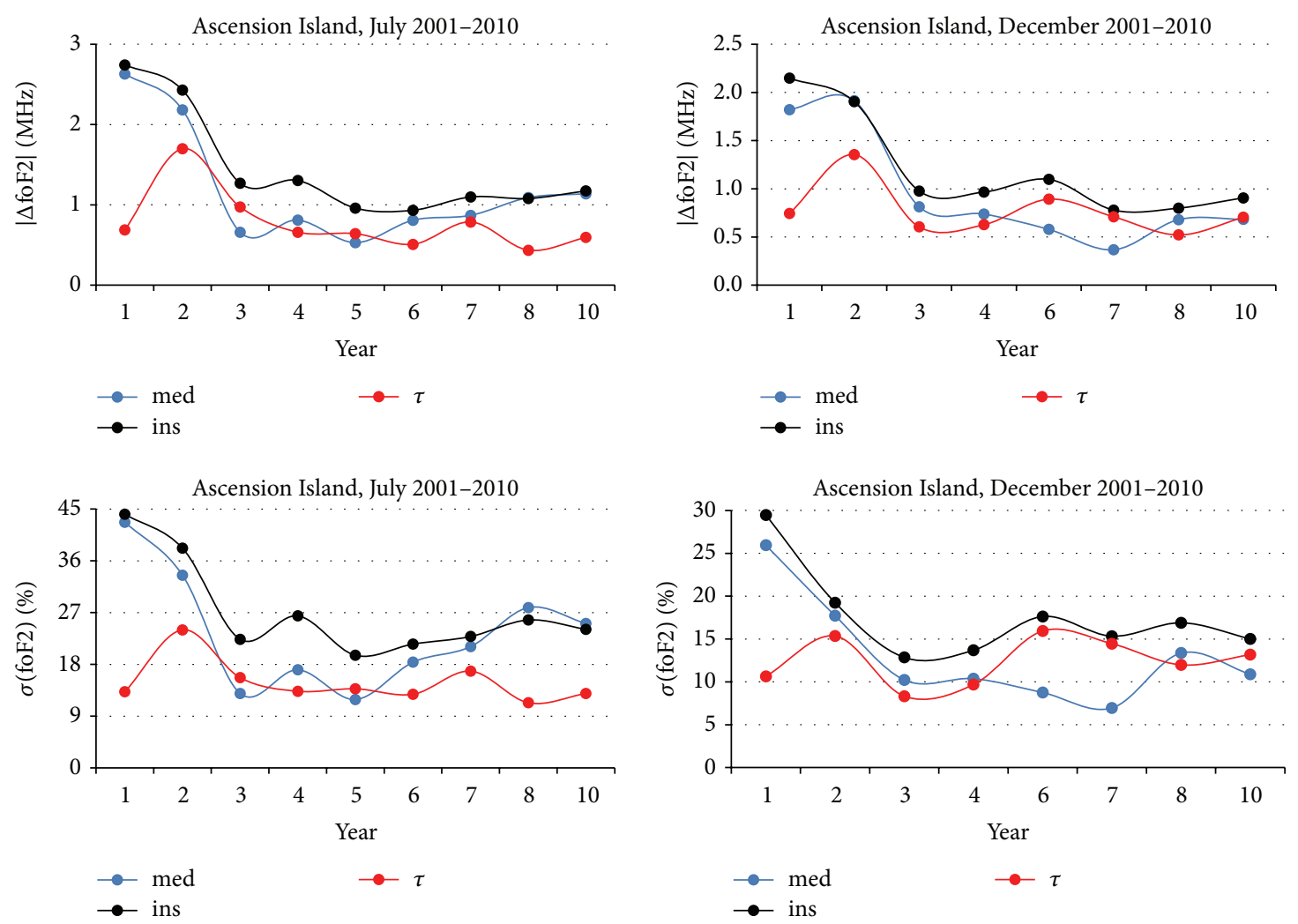

(e)

FIGURE 2: (a) Comparison of absolute and standard deviations of calculated foF2 from the experimental values for the middle-latitude station Juliusruh. (b) Comparison of absolute and standard deviations of calculated foF2 from the experimental values for the middle-latitude station Goosebay. (c) Comparison of absolute and standard deviations of calculated foF2 from the experimental values for the high-altitude station Thule. (d) Comparison of absolute and standard deviations of calculated foF2 from the experimental values for the low-latitude station Grahamstown. (e) Comparison of absolute and standard deviations of calculated foF2 from the experimental values for the equatorial station Ascension Island.

TABLE 1: An average for all years of correspondence between model and experimental foF2 values.

\begin{tabular}{lcccccccc}
\hline \multirow{2}{*}{ Station } & \multicolumn{9}{c}{ July } & \multicolumn{5}{c}{ December } \\
& $K_{\text {eff }}$ & med & ins & $\tau$ & $K_{\text {eff }}$ & med & ins & $\tau$ \\
\hline Juliusruh & 2.52 & 9.82 & 15.03 & 6.91 & 2.20 & 13.30 & 17.68 & 8.45 \\
Goosebay & 2.03 & 9.41 & 15.46 & 9.36 & 1.72 & 13.54 & 17.61 & 11.36 \\
Thule & 2.03 & 11.46 & 15.43 & 8.46 & 1.34 & 10.41 & 18.21 & 13.91 \\
Grahams & 1.70 & 9.53 & 15.84 & 10.09 & 1.99 & 12.44 & 17.26 & 9.40 \\
Ascension & 1.98 & 23.40 & 27.21 & 14.89 & 1.57 & 13.04 & 17.52 & 12.45 \\
\hline
\end{tabular}

activity period, the worse result was observed for the Goosebay station in July and December; for stations, Thule and Grahamstown, it was observed in July, for the Ascension Island station, in December. However, as shown in Table 1, it affected only MD for the equatorial station Ascension Island. This is an indication that the model of IRI in the evaluation of medians can give deviations for high- and low-latitude stations comparable with deviations for middlelatitude stations.

\section{Efficiency of $\tau$ (med) on a Global Scale}

As well as in Section 3, efficiency of $\tau$ (med) was estimated by means of absolute deviations $\mid \Delta$ foF $2 \mid$ of the calculated foF 2 values from the experimental ones and standard deviations $\sigma$ (foF2). Results are presented in Figure 3. In the left part, circles represent values of deviations of the IRI model from the experimental medians. Rhombs correspond to deviations of instantaneous foF2, calculated by the IRI model from instantaneous experimental foF2 values. Black dots show deviations for the values calculated using the observational values of TEC. An efficiency factor $K$ is shown by asterisks. The right side shows the corresponding standard deviation.

The best correspondence is obtained in the northern hemisphere. The southern hemisphere model provides a fairly large deviations which are typical for the use of $\tau$ (med). At middle latitudes of the northern hemisphere, SD values for $\tau$ (med) lie within 5\%; at high latitudes they do not exceed $10 \%$. Average values of absolute deviations of medians on globe are $0.72 \mathrm{MHz}, 1.08 \mathrm{MHz}$ for the instantaneous values, and $0.54 \mathrm{MHz}$ for $\tau$ (med) and TEC(JPL). For the other maps CODE, UPC, ESA, and IGS calculations gave 0.563, 0.613, 0.628 , and $0.569 \mathrm{MHz}$. Average SDs were $11.3 \%$ for medians, 


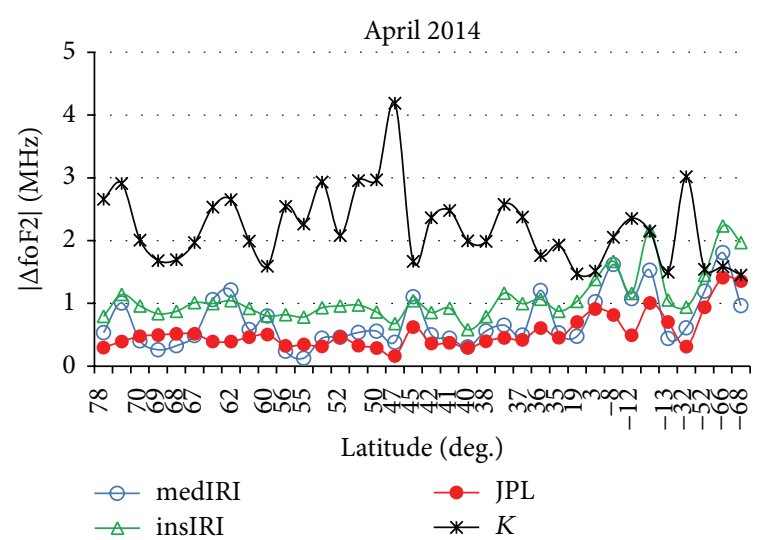

(a)

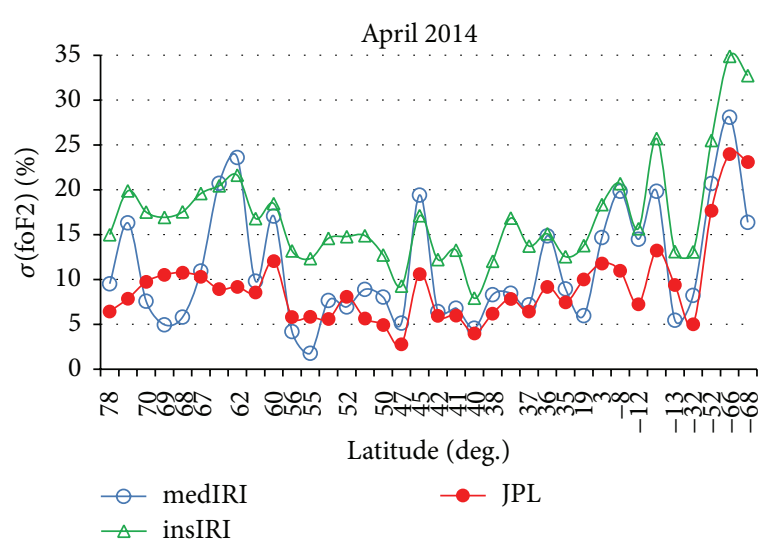

(b)

FIGURE 3: The latitudinal dependence of average absolute (a) and standard (b) deviations of the median and instantaneous values corresponding to the IRI model and global map JPL. The coefficient $K$ shows efficiency of $\tau$ (med).

$16.95 \%$ for the instantaneous values, and $9.1 \%$ for TEC(JPL). Thus, it is possible to do the intermediate conclusion: (1) the obtained results are better for all maps than for the IRI model, (2) the best result in terms of foF2 definition applies to the JPL map, the worst result applies to the ESA map, and (3) usage of IGS values does not provide improvement in comparison with individual maps JPL and CODE.

It confirms that $\tau$ (med) may be a reliable calibration coefficient of TEC on NmF2. Synchronism of foF2 and TEC variations over time is necessary for this purpose. Synchronism violation is the most probable during disturbances. Figure 4 shows the behavior of the Dst-index indicating the selected period of disturbance.

It is seen that an influence of disturbance could be expected in April 11-14th. Relative deviations $\delta$ foF2 and $\delta$ TEC (in \%) have been calculated for all stations to estimate a synchronism level. As the response of the ionosphere to disturbance may be different in various parts of globe, stations have been divided into 5 zones with the close longitudes. Zone $1\left(-15^{\circ} \mathrm{E}<\lambda<15^{\circ} \mathrm{E}\right)$ includes five stations, four of which belong to the European region. Most of these stations (12) enter in zone $2\left(15^{\circ} \mathrm{E}<\lambda<40^{\circ} \mathrm{E}\right)$ including Russian part; zone $3\left(60^{\circ} \mathrm{E}<\lambda<100^{\circ} \mathrm{E}\right)$ included three Siberian stations and two stations of southern hemisphere. Zone $4\left(110^{\circ} \mathrm{E}<\lambda<170^{\circ} \mathrm{E}\right)$ included 11 stations of the Far East and South-East regions and zone $5\left(60^{\circ} \mathrm{W}<\lambda<80^{\circ} \mathrm{W}\right)$ consists of the American stations. Figure 3 shows the absolute deviations averaged over the month. To assess the synchronism deviations are needed for specific days. Figure 5 shows $\delta$ foF 2 and $\delta$ TEC for zones 2 and 4 with the largest number of stations for a few periods connected to disturbance.

It may be noted that serial patterns in a daily course allow for studying the ionosphere response in details. On the eve of disturbance on April 11th in UT $=12$, deviations do not exceed the values inherent in quiet conditions. At the time of UT = 18 disturbance has already begun to capture zone 2. The negative disturbance is developing in a high-latitude area. There is the positive disturbance in middle-latitude region, but synchronism is maintained almost all the time.

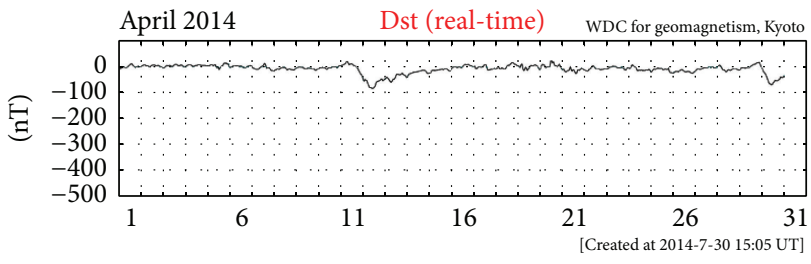

FIgUre 4: Behavior of Dst-index in April 2014.

At night $(\mathrm{UT}=0)(04.12 .2014)$ the high-latitude area of zone 2 responds to the large negative deviations which peak in the morning (UT $=6)$. Zone 4 also reacted in the form of the negative disturbance by a smaller force; that is, disturbance had a global character. In the second half of 04.12.2014 and in the first half of 4.13.2014 character of variations is preserved by maintaining synchronism. On April 15th the ionosphere is back to a quiet state practically on a global scale. The average for the whole day deviations of calculated foF2 from the experimental values is presented in Figure 6 for all stations. The dots show results for the initial IRI model and circles represent average monthly deviations for foF 2 values, calculated with usage of $\tau$ (med) and observational TEC(obs). The other curves refer to these deviations for specific days.

In some regions, the response to disturbance began to appear on April 11th and, nevertheless, for this day deviations were less than averages for the month. The same is seen also for a quiet day on April 15th. On the day of perturbations on April 12th deviations exceed averages but in the vast majority they were less than deviations for the IRI model. Of certain interest are cases where use of $\tau$ (med) does not strongly improve values for the IRI model. It is connected very often with wrong automatic scaled samples. It turned out that in a case with the station Darwin $\left(-12.5^{\circ} \mathrm{S}, 131^{\circ} \mathrm{E}\right)$ it is not an error but twice enhanced ionization which led to the large increase of TEC. For this specific day $\mid \Delta$ foF2(IRI) $\mid$ is equal to $2.435 \mathrm{MHz}$ and $\mid \Delta$ foF $2(\mathrm{rec}) \mid=1.766 \mathrm{MHz}$. To confirm this fact and an estimation of a possible zone of increased foF2, 
11 April 2014, UT $=12$
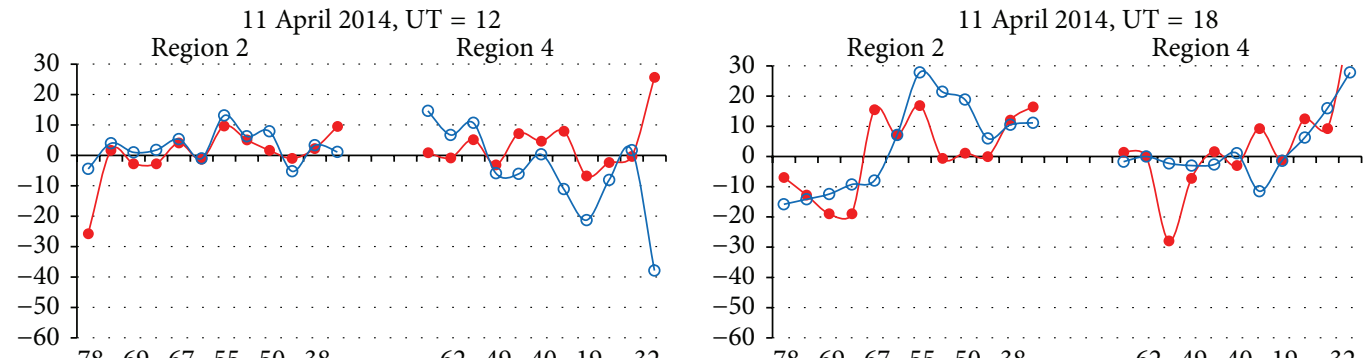

Latitude (deg.)

12 April 2014, UT = 0

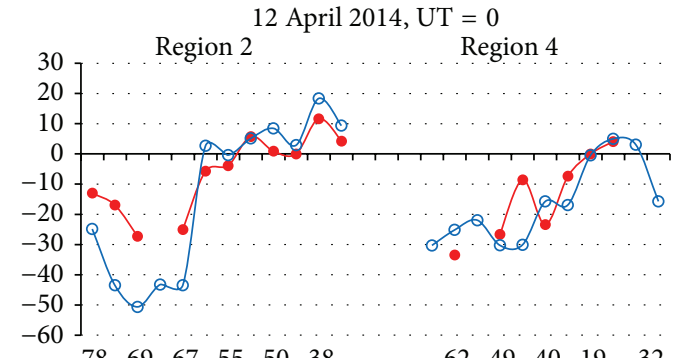

$\begin{array}{lllllllllll}78 & 69 & 67 & 55 & 50 & 38 & 62 & 49 & 40 & 19 & -32\end{array}$

Latitude (deg.)

12 April 2014, UT $=12$

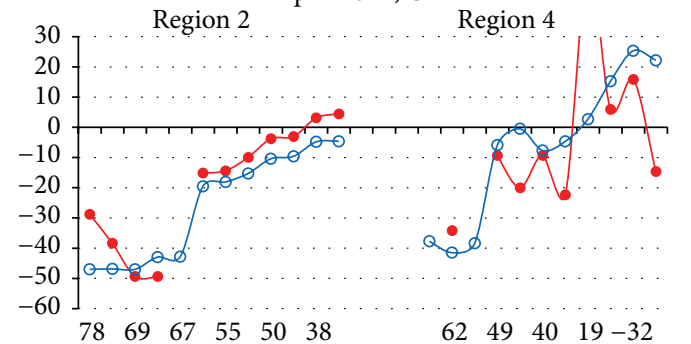

Latitude (deg.)

13 April 2014, UT $=0$

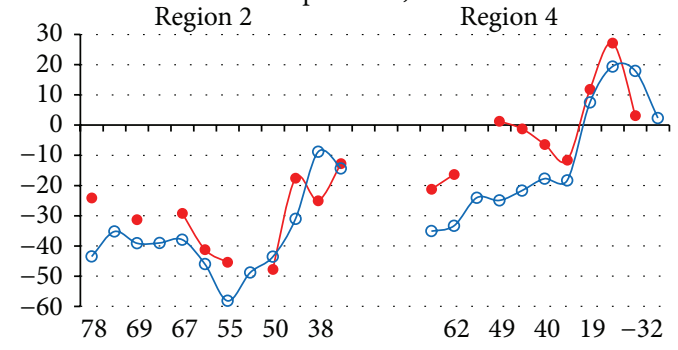

Latitude (deg.)

$\begin{array}{lllll}62 & 49 & 40 & 19 & -32\end{array}$

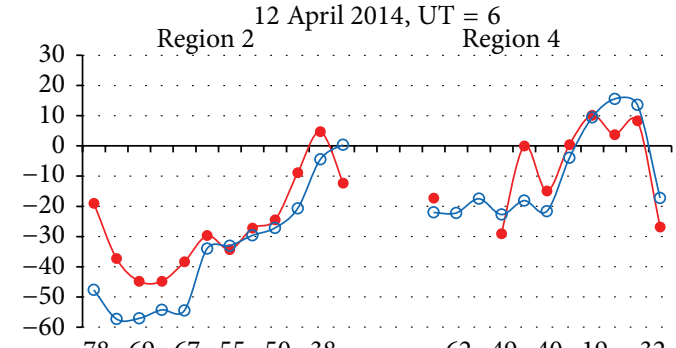

$\begin{array}{llllllllllll}78 & 69 & 67 & 55 & 50 & 38 & 62 & 49 & 40 & 19 & -32\end{array}$

Latitude (deg.)

12 April 2014, UT $=18$

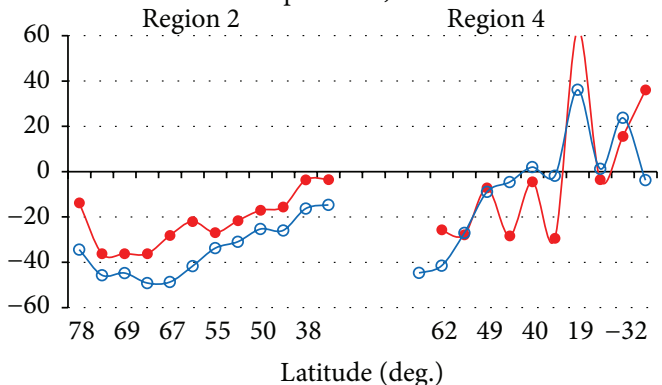

Latitude (deg.)

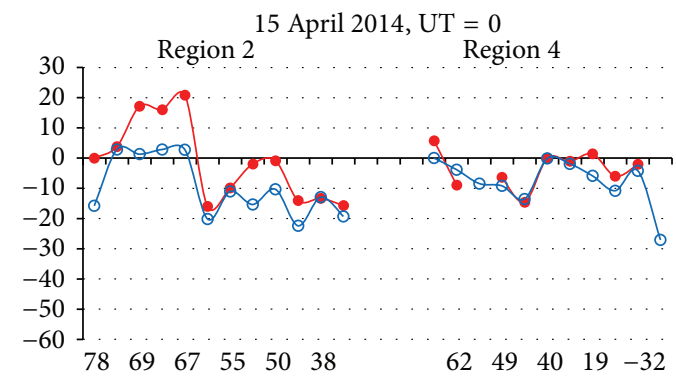

Latitude (deg.)

15 April 2014, UT $=12$

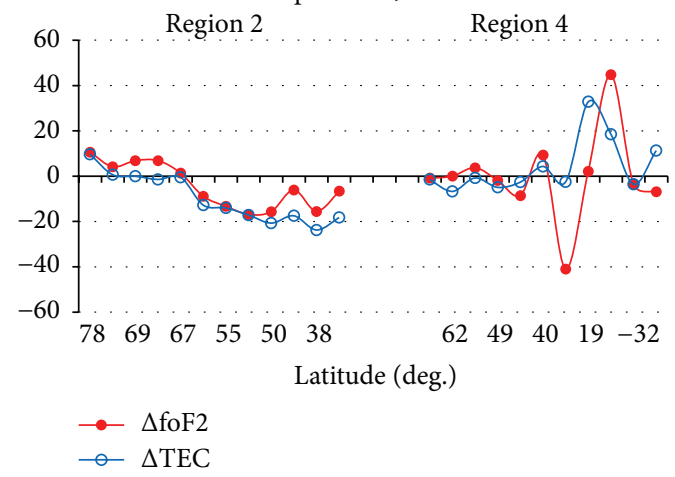

FIGURE 5: Behavior of $\delta$ foF2 and $\delta$ TEC, illustrating synchronism of variations, during a few periods. 


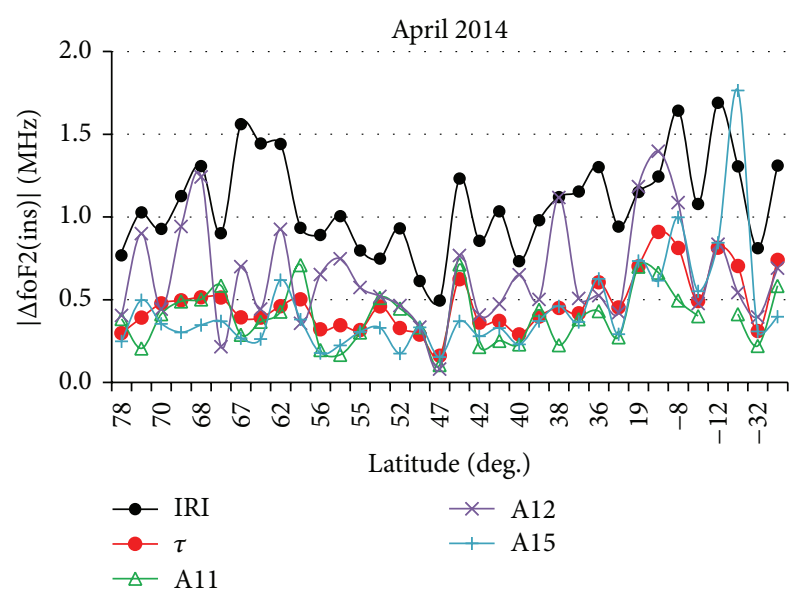

Figure 6: Deviations of foF2 calculated from experimental values around the period of disturbance.

values of TEC(JPL) have been calculated in increments of $2.5^{\circ}$ latitude and $5^{\circ}$ longitude from the starting point with coordinates $\left(-12.5^{\circ} \mathrm{S}, 130^{\circ} \mathrm{E}\right)$. Results are given in Figure 7 as a comparison of the instantaneous and median values.

There is a local enough zone on latitude, as well as on a longitude. At the large longitudes daily difference of the instantaneous and median values may already play a role. It is confirmed by behavior of parameters at the Cocos station, which is at two hours west Darwin. In this case values of $\tau$ (med) for two stations were coincided in UT $=9$; hence, its $\tau$ (med) can be used for calculation of appropriate gain of foF2.

\section{On the Possible Global Model of the Equivalent Slab Thickness of the Ionosphere}

Despite an important role of the equivalent slab thickness of the ionosphere (see, e.g., $[28,29]$ ), empirical models of $\tau$ (med) actually do not exist. It is possible to point out the model developed for the European region for the noon and midnight values as linear functions $y=a * x+b[30$, 31]. Factors $a$ and $b$ of these functions are given in [20] in the form of tables for four years $(1996,1999,2000$, and 2004). According to European GPS stations, in [31] linear dependence of TEC on solar activity has been found in quiet conditions $(\tau \mathrm{O}): \tau o=k *\left(\cos _{\chi 12}\right)^{m}$, where $\cos _{\chi 12}$ is cosine of zenith angle in the noon representing seasonal parameter. Expressions $\tau=370 *\left(\cos _{\chi 12}\right)^{0.44}$ for day conditions and $\tau=\left(313 * \cos _{\chi 12}\right)^{-0.24}$ for the night were obtained. In [32] it is shown that use of this empirical model allows to correct the IRI model with use of observational values TEC(obs) and to fill gaps in the foF2 data of vertical sounding.

Results obtained in the present paper allow us to raise the issue of the global model of $\tau$ (med). Currently, two models (the Neustrelitz Global Model NGM and IRI-Plas) may be applied for this role. A brief description of these models is as follows. The NGM model was developed in the form of separate models for TEC [33] and foF2 [34].
Value $\tau(\mathrm{NGM})$ is obtained from the relation $\tau(\mathrm{NGM})=$ TEC (NGM)/NmF2(NGM). The global model of TEC(NGM) was constructed on the basis of values of the global map CODE and is given by product of 5 coefficients: TEC $=\mathrm{F} 1 *$ $\mathrm{F} 2 * \mathrm{~F} 3 * \mathrm{~F} 4 * \mathrm{~F} 5$. Each coefficient reflects dependence on the certain physical factor and is calculated with use from 2 to 6 coefficients $\mathrm{Ci}$. Coefficients were calculated by a method of the least squares superimposition on observational data for some years. Coefficient F1 describes dependence on local time LT, that is, on a zenith angle of the sun. Factor F2 shows annual and semiannual variations of TEC. Factor F3 describes dependence of TEC on geomagnetic latitude. Factor F4 takes into account an equatorial anomaly in latitudinal course of TEC. Factor F5 describes dependence of TEC on solar activity for what coefficient F10.7 was chosen. 14 coefficients are necessary only. The model for NmF2 [34] is constructed by the same principle but includes 13 coefficients as in this case a factor of daily course F1 includes 6 coefficients. Coefficients are given in papers [33, 34]. The IRI-Plas model is an updating version of the IRI model, that is, version IRI2010 [10], in which the model $[9,16]$ has introduced. The program of this model is on a website $\mathrm{ftp}$ //ftp.izmiran.rssi.ru/pub/izmiran/SPIM/. Main advantage of this model is the consideration of the plasmaspheric part of the $\mathrm{N}(\mathrm{h})$-profile and also ability of its adaptation to the observational parameters of the ionosphere: critical frequency foF2, maximum height hmF2, and TEC. Adaptation to TEC is a new option that allows for specifying shape of $N(h)$ profile more accurately. Some results of testing these models are presented in [35]. It is shown that there are certain regions and time periods when one or another model provides the better results than the initial IRI model, and results strongly depend on a season and level of solar activity. In the current paper these results are supplemented by comparison of these two models with observational data on a global scale in April 2014 in Figure 8. Figure 8 shows absolute deviations for the initial IRI model, two tested models, and deviations for the use of $\tau$ (med) for map JPL.

In the given conditions, the IRI-Plas model provides good agreement with observations in auroral region of the northern hemisphere. Both models have shown good agreement in middle latitudes; in low-latitude region slightly better results are provided with the NGM model. At the same time, a reason of large deviations of the NGM model for stations Thule, Zhigansk, Yakutsk, and Wakkanai remains unclear.

\section{Discussion and Conclusions}

In the present paper the critical frequency definition from the observational TEC values is based on use of the observational median of the equivalent slab thickness $\tau$ (med). This parameter is determined by TEC and NmF2. A lot of papers were devoted to $\tau$ (med) behavior using ionosonde/GPS or even COSMIC radio occultation data (e.g., [30, 31, 36-40]). Results concern diurnal, seasonal variations and solar and latitudinal dependences. It is worth noting two aspects. Firstly, some articles contain incorrect or ill-founded results. For example, [38] shows the diurnal course of $\tau$ (med) for the 

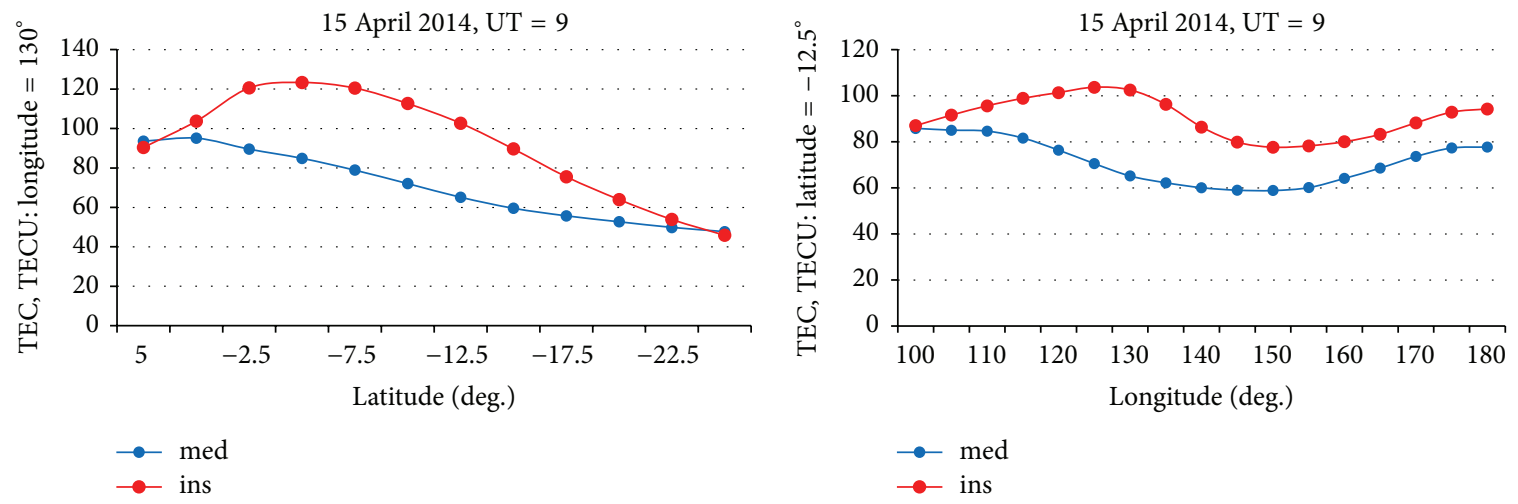

FIGURE 7: Latitude-longitudinal localization of increased ionization area.

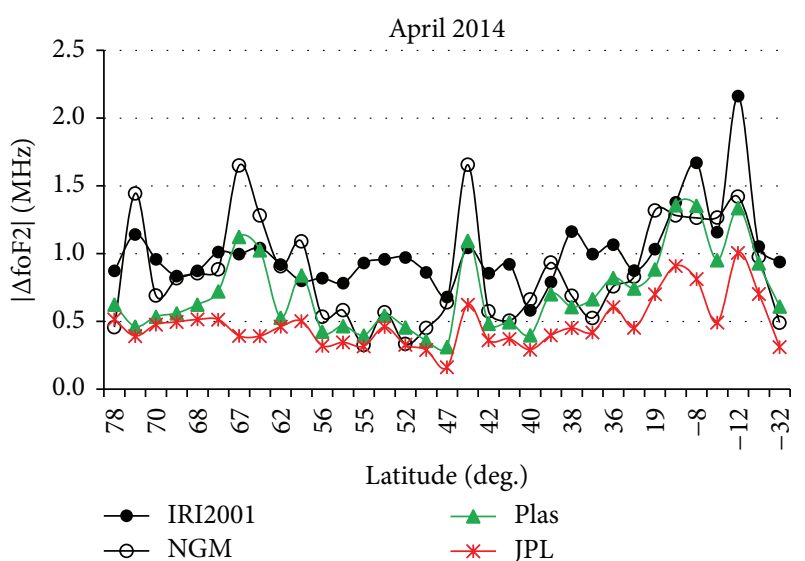

FIgURE 8: Comparison of absolute deviations of calculated foF2 values from observational ones for various models and at use of $\tau$ (med) for map JPL.

three European stations, Ebre, El-Arenosillo, and Pruhonice, for three seasons of 2007 (winter, equinox, and summer), obtained by the LaPlata method [41]. Presence of dawn maximum is supported by the data of all global maps and weak dawn maximum is displayed even in a diurnal course of $\tau$ (IRI), but the curves of [38] showed the opposite changes. The paper [39] shows the results using ionosonde/GPS measurements to calculate $\tau(\mathrm{med})$ in the European region. The calculation was performed without considering latitudinal dependence of $\tau$. The absence of latitudinal dependence was underlined by other authors, and the same was done for the European region [39], but it is crucial for definition of foF2 from TEC(obs) using median $\tau$ (med). If the latitudinal dependence $\tau$ (med) did not exist, then $\tau$ (med) of any ionospheric station could be used throughout all region to determine foF2, for example, by operating system LIEDR (Local Ionospheric Electron Density Reconstruction), which monitors $\tau$ [28]. "The absence of latitudinal dependence" of $\tau$ (med) is illustrated in Figure 9 for stations lying between latitudes used in [39] for January and July 2008.
In [40], possibly, the first results were obtained using the data of radio occultation (RO) measurements and ionosondes. They belong to three seasons of 2007 (winter, summer, and equinox). Figure 10 compares results of RO and global map.

It can be seen that the use of $\tau$ according radio occultation measurement will not lead to satisfactory results. Secondly, parameter $\tau$ (med) was not used to determine foF 2 from TEC(obs).

Earlier studies [18-20] have shown that such use allows us to improve significantly the correspondence between the calculated and observational values of foF 2 results have been obtained according to the European stations. Occurrence of new ionospheric stations in 2013-2014 allows to estimate efficiency of $\tau$ (med) on a global scale. As the greatest interest is caused by a situation during disturbances because of possible violation of synchronism of foF2 and TEC variations, the April 2014 including disturbance with minimal Dst $=-80 \mathrm{nT}$ was chosen. The basic results are as follows. (1) Relative variations $\delta$ foF 2 and $\delta$ TEC obtained according to more than 40 stations in April 2014 have shown that disturbance was global with different strength in various regions; however synchronism of foF2 and TEC variations was maintained everywhere that allows using $\tau$ (med) as a reliable calibration coefficient. (2) The efficiency coefficient of joint usage of $\tau$ (med) and TEC(obs) changes from 1.5 to 4 with average value 2.2 across the globe. The highest coefficient corresponds to middle latitudes; however the estimations obtained for high-and low-latitude areas indicate the possibility of using $\tau$ (med) and TEC(obs) in these areas. This will be especially effective when using local models of foF2 type [42-45]. (3) For example, the Darwin station showed that TEC may be used to control local ionospheric conditions, in case of the ionospheric stations in a certain area, and to estimate the corresponding response of foF2, connected to geomagnetic disturbance. (4) As the expected solar activity will not be very high under the forecast (http://solarscience.msfc.nasa.gov/predict.shtml and [46]), it is possible to use of $\tau$ (med) in some latitudinal range because in this case obtained $\tau$ (med) will be closer to $\tau$ (obs) than $\tau$ (IRI). (5) Final choice of a global model for $\tau$ (med) is complicated by the strong dependence of results on a season 

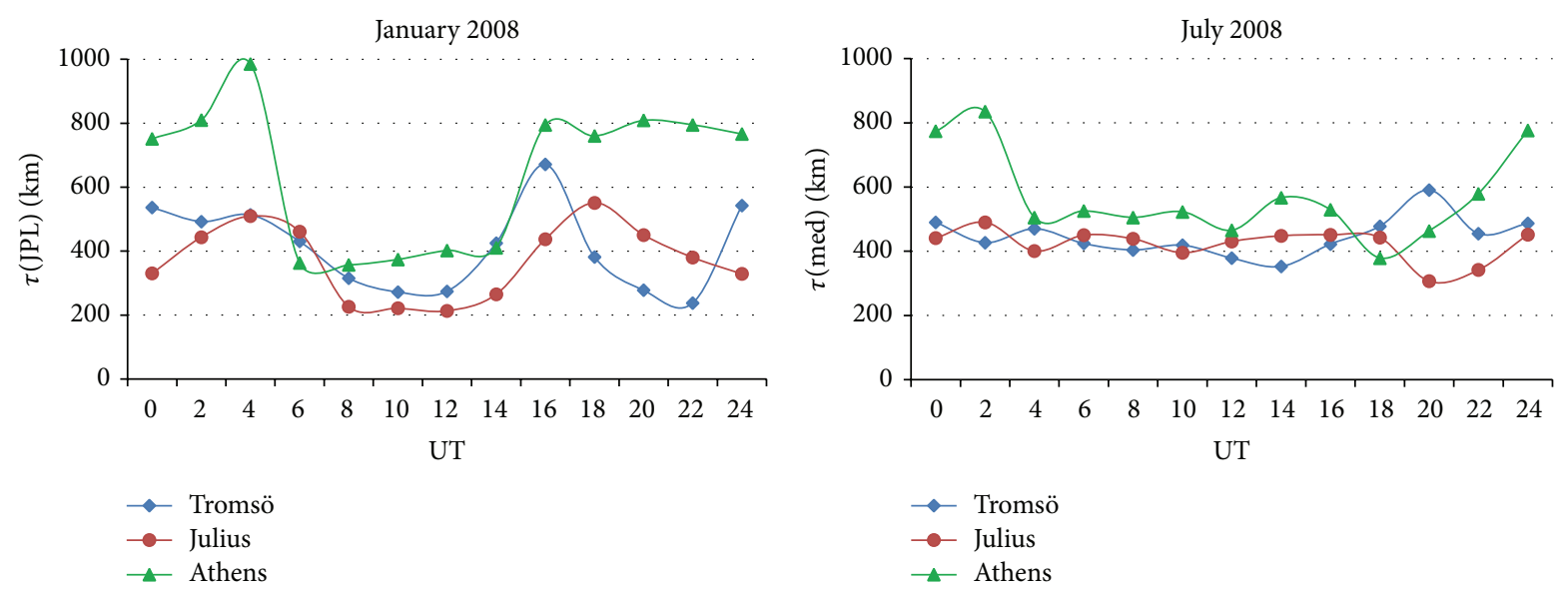

FIGURE 9: Illustration of differences of $\tau$ for stations with different latitudes.
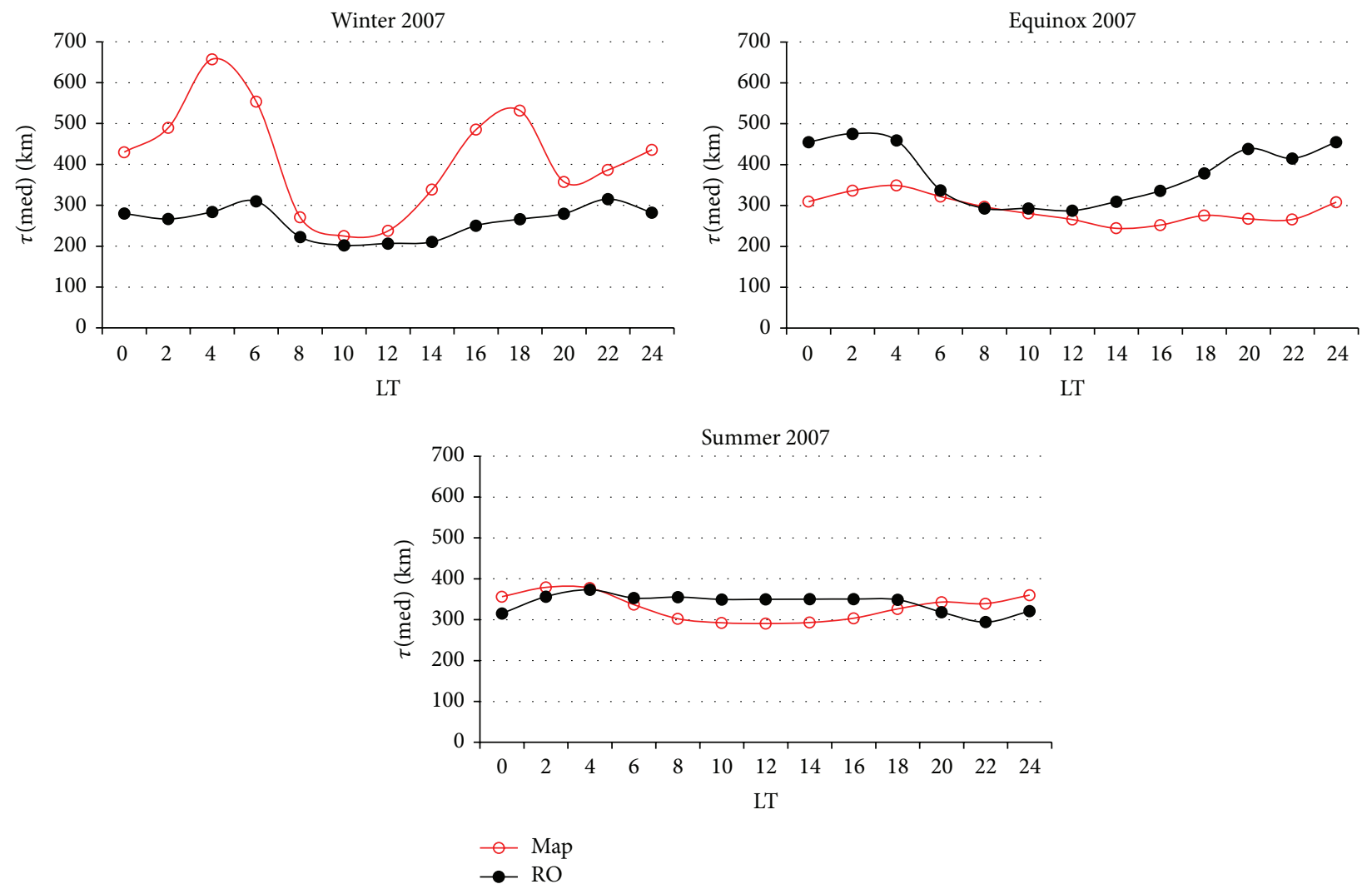

FIGURE 10: Comparison of $\tau$ according to radio occultation measurements and averaging the values of global maps for specific stations and three seasons.

and solar activity. For April 2014 conditions the IRI-Plas model can produce results, comparable with usage of $\tau$ (med) in auroral zone of the northern hemisphere. Both approaches (IRI-Plas and NGM) give the same results in middle latitudes. In an equatorial zone the NGM model gives slightly better results, but in general problems in the simulation of foF2 in southern hemisphere remain.

The given discussion would be incomplete without a comment on the accuracy of TEC values. In this paper, vertical values of VTEC converted from slant STEC were used. One of inaccuracies of VTEC definition is imported by the conversion function based on a model of a thin shell at a fixed height and a selection of this height. However the basic reasons are hardware-associated biases (delays in satellite transmitters and receivers: differential code biases (DCB)). There are many methods and their estimates. We will give some of them. In [47], the estimate of accuracy was performed for one of the basic methods of DCB definition 
$[48,49]$ to reveal latitudinal dependences. It has appeared that such dependence exists. The root mean square for satellite biases in middle latitudes was $\sim 1$ TECU and for receivers it was $\sim 2$ TECU. Near to equatorial anomaly these biases were 2TECU and 3-4TECU in 2004. In [50], the method for a polar region was proposed and its comparison with other methods was carried out. For this purpose $\mathrm{N}(\mathrm{h})$-profiles of an incoherent scatter radar (ISR) in Resolute Bay were used. The method [50] has given correspondence of VTEC(ISR) with the observational values within 1 TECU. This value is close to an estimate of standard methods (e.g., [51, 52]). Other two methods $[49,53]$ have led to the errors sometimes exceeding 6 TECU. The method [49] has given deviations from VTEC(ISR) in the range $-1.5 \pm-3.0$ TECU. The method [53] has given differences in the range $-2.1 \pm-6.4$ TECU. From the recent reviews it may be noted $[54,55]$. In [54] for 60 stations the relative contribution of various factors (mathematical functions of the spatial distribution of VTEC, methods of data processing, and different sizes of networks) in estimation errors of receiver DCB is reviewed in details. It is indicated that direct measurement of biases would give the precision of 0.1 TECU. As there were no reference values, DCB calculated were compared with biases for the global map IGS [56]. Conformity was within 3-4 TECU. It is shown that the combined influence of factors can lead to differences DCB between stations on a global scale in the range $-2.5 \div+14$ TECU. The largest contribution comes from inaccuracies related to a spatial distribution of receivers. In [55] methods of authors were compared also with IGS. Correspondence was within 1 TECU. Nevertheless, authors [55] have indicated that "more studies are needed to ensure the reliability and stability of the estimated receiver DCBs." Coefficient $\tau$ (med) calibrates values of TEC in according to parameter foF2. This calibration is an advantage of coefficient $\tau$ (med), mitigating the dependence of obtained foF2 on accuracy of TEC definition.

\section{Conflict of Interests}

The authors declare that there is no conflict of interests regarding the publication of this paper.

\section{Acknowledgments}

Authors thank International GNSS Service (IGS) for GPS data and products, groups of scientists providing the data for SPIDR database, models IRI and NGM, and Dr. Tamara Gulyaeva for IRI Plas code. This work was supported by project of Southern Federal University no. 213.01-11/2014-22.

\section{References}

[1] L. Kersley, D. Malan, S. E. Pryse et al., "Total electron contenta key parameter in propagation: measurement and use in ionospheric imaging," Annals of Geophysics, vol. 47, no. 2-3, pp. 1067-1091, 2004.

[2] T. L. Gulyaeva and I. Stanislawska, "Derivation of a planetary ionospheric storm index," Annales Geophysicae, vol. 26, no. 9, pp. 2645-2648, 2008.
[3] A. Devyatkin, I. Gotur, V. Krasnov, Y. Kuleshov, and A. Meshkov, "Ionospheric total electron content modelling and the estimation of errors in coordinate measuring caused by solar activity in remote sensing," International Journal of Remote Sensing, vol. 35, no. 15, pp. 5913-5925, 2014.

[4] T. Durgonics, G. Prates, and M. Berrocoso, "Detection of ionospheric signatures from GPS-derived total electron content maps," Journal of Geodetic Science, vol. 4, no. 1, pp. 98-108, 2014.

[5] A. K. Shukla, S. Das, R. V. Khekale, M. R. Sivaraman, and K. Bandyopadhyay, "Effect of grid size variation on the interpolation of the total electron content over the Indian region," Navigation, vol. 57, no. 2, pp. 115-122, 2010.

[6] N. YảAcob, M. Abdullah, I. Mahamod, and A. Zaharim, "Model validation for GPS total electron content (TEC) using 10th polynomial function technique at an equatorial region," WSEAS Transactions on Computers, vol. 8, no. 9, pp. 1533-1542, 2009.

[7] S. Gowsuddin and V. B. S. Srilatha Indira Dutt, "Ionospheric parameters estimation for accurate GPS navigation solution," International Journal of Engineering and Advanced Technology, vol. 2, no. 2, pp. 302-305, 2012.

[8] B. V. Troitsky, M. Y. Ortikov, K. A. Lobanov, A. A. Vlasov, and A. I. Pogorel'tsev, "Ionospheric support of HF radiocommunication using maps of total electron content," Geomagnetism and Aeronomy, vol. 47, no. 3, pp. 389-394, 2007.

[9] T. L. Gulyaeva, X. Huang, and B. W. Reinisch, "Ionosphereplasmasphere model software for ISO," Acta Geodaetica et Geophysica Hungarica, vol. 37, no. 2-3, pp. 143-152, 2002.

[10] T. L. Gulyaeva and D. Bilitza, "Towards ISO standard earth ionosphere and plasmasphere model," in New Developments in the Standard Model, pp. 1-48, Nova Science Publishers, 2012, https://www.novapublishers.com/catalog/product_info.php?products_id=35812.

[11] B. Khattatov, M. Murphy, M. Gnedin et al., "Ionospheric nowcasting via assimilation of GPS measurements of ionospheric electron content in a global physics-based time-dependent model," Quarterly Journal of the Royal Meteorological Society, vol. 131, no. 613, pp. 3543-3559, 2006.

[12] T. Fuller-Rowell, E. Araujo-Pradere, C. Minter et al., "US-TEC: a new data assimilation product from the Space Environment Center characterizing the ionospheric total electron content using real-time GPS data," Radio Science, vol. 41, no. 6, Article ID RS6003, 2006.

[13] M. J. Angling, J. Shaw, A. K. Shukla, and P. S. Cannon, "Development of an HF selection tool based on the Electron Density Assimilative Model near real-time ionosphere," Radio Science, vol. 44, no. 4, Article ID RS0A13, 2009.

[14] D. Bilitza, "International reference ionosphere," Radio Science, vol. 36, no. 2, pp. 261-275, 2001.

[15] L. F. McNamara, "The use of total electron content measurements to validate empirical models of the ionosphere," Advances in Space Research, vol. 5, no. 7, pp. 81-90, 1985.

[16] Z. Houminer and H. Soicher, "Improved short-term predictions of $\mathrm{f}_{0} \mathrm{~F}_{2}$ using GPS time delay measurements," Radio Science, vol. 31, no. 5, pp. 1099-1108, 1996.

[17] T. L. Gulyaeva, "International standard model of the Earth's ionosphere and plasmasphere," Astronomical and Astrophysical Transactions, vol. 22, pp. 639-643, 2003.

[18] O. A. Maltseva, N. S. Mozhaeva, O. S. Poltavsky, and G. A. Zhbankov, "Use of TEC global maps and the IRI model to study ionospheric response to geomagnetic disturbances," Advances in Space Research, vol. 49, no. 6, pp. 1076-1087, 2012. 
[19] A. Krankowski, I. I. Shagimuratov, and L. W. Baran, "Mapping of foF2 over Europe based on GPS-derived TEC data," Advances in Space Research, vol. 39, no. 5, pp. 651-660, 2007.

[20] O. A. Maltseva, N. S. Mozhaeva, and T. V. Nikitenko, "Comparison of model and experimental ionospheric parameters at high latitudes," Advances in Space Research, vol. 51, no. 4, pp. 599-609, 2013.

[21] L. F. McNamara, D. T. Decker, J. A. Welsh, and D. G. Cole, "Validation of the Utah State University Global Assimilation of Ionospheric Measurements (GAIM) model predictions of the maximum usable frequency for a $3000 \mathrm{~km}$ circuit," Radio Science, vol. 42, no. 3, 2007.

[22] R. O. Conkright and L. F. McNamara, "Quality control of automatically scaled vertical incidence ionogram data," Radio Science, vol. 32, no. 5, pp. 1997-2002, 1997.

[23] Z. Chen, S. Wang, S. Zhang, G. Fang, and J. Wang, "Automatic scaling of F layer from ionograms," Radio Science, vol. 48, no. 3, pp. 334-343, 2013.

[24] L. Liu, Y. Chen, H. Le, V. I. Kurkin, N. M. Polekh, and C.-C. Lee, "The ionosphere under extremely prolonged low solar activity," Journal of Geophysical Research, vol. 116, Article ID A04320, 2011.

[25] L. R. Cander and L. Ciraolo, "Ionospheric total electron content and critical frequencies over Europe at solar minimum," Acta Geophysica, vol. 58, no. 3, pp. 468-490, 2010.

[26] I. E. Zakharenkova, A. Krankowski, D. Bilitza, I. V. Cherniak, I. I. Shagimuratov, and R. Sieradzki, "Comparative study of foF2 measurements with IRI-2007 model predictions during extended solar minimum," Advances in Space Research, vol. 51, no. 4, pp. 620-629, 2013.

[27] O. A. Maltseva, N. S. Moshaeva, and T. N. Nikitenko, "On propagation of radio waves during period of extremely low solar activity," Electromagnetic Waves and Electronic Systems, vol. 17, no. 6, pp. 40-47, 2012 (Russian).

[28] S. M. Stankov and R. Warnant, "Ionospheric slab thicknessanalysis, modelling and monitoring," Advances in Space Research, vol. 44, no. 11, pp. 1295-1303, 2009.

[29] A. Belehaki, I. Tsagouri, I. Kutiev, and P. Marinov, "An improved model for operational specification of the electron density structure up to geosynchronous heights," Final Report AOARD Contract FA5209-09-P-0253, 2010.

[30] S. S. Kouris, K. V. Polimeris, L. R. Cander, and L. Ciraolo, "Solar and latitude dependence of TEC and SLAB thickness," Journal of Atmospheric and Solar-Terrestrial Physics, vol. 70, no. 10, pp. 1351-1365, 2008.

[31] S. S. Kouris, K. V. Polimeris, L. Ciraolo, and D. N. Fotiadis, "Seasonal dependence of TEC and SLAB thickness," Advances in Space Research, vol. 44, no. 6, pp. 715-724, 2009.

[32] O. A. Maltseva, G. A. Zhbankov, and T. Trinh Quang, "Improvement of the real time total electron content based on the International Reference Ionosphere model," Advances in Space Research, vol. 46, no. 8, pp. 1008-1015, 2010.

[33] N. Jakowski, M. M. Hoque, and C. Mayer, "A new global TEC model for estimating transionospheric radio wave propagation errors," Journal of Geodesy, vol. 85, no. 12, pp. 965-974, 2011.

[34] M. M. Hoque and N. Jakowski, "A new global empirical NmF2 model for operational use in radio systems," Radio Science, vol. 46, no. 6, Article ID RS6015, 13 pages, 2011.

[35] O. A. Maltseva, N. S. Mozhaeva, and T. V. Nikitenko, "Comparative analysis of two new empirical models: IRI-Plas and NGM (the Neustrelitz Global Model)," Advances in Space Research, vol. 55, no. 8, pp. 2086-2098, 2015.
[36] B. Jayachandran, T. N. Krishnankutty, and T. L. Gulyaeva, "Climatology of ionospheric slab thickness," Annales Geophysicae, vol. 22, no. 1, pp. 25-33, 2004.

[37] T. Gulyaeva and I. Stanislawska, "Night-day imprints of ionospheric slab thickness during geomagnetic storm," Journal of Atmospheric and Solar-Terrestrial Physics, vol. 67, no. 14, pp. 1307-1314, 2005.

[38] M. Mosert, S. Magdaleno, D. Buresova et al., "Behavior of the equivalent slab thickness over three European stations," Advances in Space Research, vol. 51, no. 4, pp. 677-682, 2013.

[39] P. Vryonides, C. Tomouzos, G. Pelopida, and H. Haralambous, "Investigation of ionospheric slab thickness and plasmaspheric TEC using satellite measurements," in Proceedings of the Progress in Electromagnetics Research Symposium (PIERS '12), pp. 1172-1175, Moscow, Russia, August 2012.

[40] P. Guo, X. Xu, and G. X. Zhang, "Analysis of the ionospheric equivalent slab thickness based on ground-based GPS/TEC and GPS/COSMIC RO measurements," Journal of Atmospheric and Solar-Terrestrial Physics, vol. 73, no. 7-8, pp. 839-846, 2011.

[41] C. Brunini, A. Meza, F. Azpilicueta, M. A. van Zele, M. Gende, and A. Díaz, "A new ionosphere monitoring technology based on GPS," Astrophysics and Space Science, vol. 290, no. 3-4, pp. 415-429, 2004.

[42] B. Zolesi, L. R. Cander, and G. D. Franceschi, "Simplified ionospheric regional model for telecommunication applications," Radio Science, vol. 28, no. 4, pp. 603-612, 1993.

[43] P. K. Bhuyan and S. Baruah, "A regional mapping of the foF2 over India as an additional input to IRI," Advances in Space Research, vol. 18, no. 6, pp. 205-208, 1996.

[44] X. Yue, W. Wan, L. Liu, and B. Ning, "An empirical model of ionospheric foE over Wuhan," Earth, Planets and Space, vol. 58, no. 3, pp. 323-330, 2006.

[45] A. O. Adewale, E. O. Oyeyemi, and L. A. McKinnell, "Comparisons of observed ionospheric F2 peak parameters with IRI2001 predictions over South Africa," Journal of Atmospheric and Solar-Terrestrial Physics, vol. 71, no. 2, pp. 273-284, 2009.

[46] J. Uwamahoro, L.-A. McKinnell, and P. J. Cilliers, "Forecasting solar cycle 24 using neural networks," Journal of Atmospheric and Solar-Terrestrial Physics, vol. 71, no. 5, pp. 569-574, 2009.

[47] D. H. Zhang, W. Zhang, Q. Li, L. Q. Shi, Y. Q. Hao, and Z. Xiao, "Accuracy analysis of the GPS instrumental bias estimated from observations in middle and low latitudes," Annales Geophysicae, vol. 28, no. 8, pp. 1571-1580, 2010.

[48] A. J. Mannucci, B. D. Wilson, D. N. Yuan, C. H. Ho, U. J. Lindqwister, and T. F. Runge, "A global mapping technique for GPS-derived ionospheric total electron content measurements," Radio Science, vol. 33, no. 3, pp. 565-582, 1998.

[49] G. Ma and T. Maruyama, "Derivation of TEC and estimation of instrumental biases from GEONET in Japan," Annales Geophysicae, vol. 21, no. 10, pp. 2083-2093, 2003.

[50] D. R. Themens, P. T. Jayachandran, R. B. Langley, J. W. MacDougall, and M. J. Nicolls, "Determining receiver biases in GPS-derived total electron content in the auroral oval and polar cap region using ionosonde measurements," GPS Solutions, vol. 17, no. 3, pp. 357-369, 2013.

[51] D. S. Coco, C. Coker, S. R. Dahlke, and J. R. Clynch, "Variability of GPS satellite differential group delay biases," IEEE Transactions on Aerospace and Electronic Systems, vol. 27, no. 6, pp. 931938, 1991.

[52] X. F. Ma, T. Maruyama, G. Ma, and T. Takeda, "Determination of GPS receiver differential biases by neural network parameter 
estimation method," Radio Science, vol. 40, no. 1, Article ID RS1002, 2005.

[53] G. E. Lanyi and T. Roth, "Comparison of mapped and measured total ionospheric electron content using global positioning system and beacon satellite observations," Radio Science, vol. 23, no. 4, pp. 483-492, 1988.

[54] S. Kao, Y. Tu, W. Chen, D. J. Weng, and S. Y. Ji, "Factors affecting the estimation of GPS receiver instrumental biases," Survey Review, vol. 45, no. 328, pp. 59-67, 2013.

[55] B.-K. Choi, J.-U. Park, K. M. Roh, and S.-J. Lee, "Comparison of GPS receiver DCB estimation methods using a GPS network," Earth, Planets and Space, vol. 65, no. 7, pp. 707-711, 2013.

[56] M. Hernández-Pajares, J. M. Juan, J. Sanz et al., "The IGS VTEC maps: a reliable source of ionospheric information since 1998," Journal of Geodesy, vol. 83, no. 3-4, pp. 263-275, 2009. 

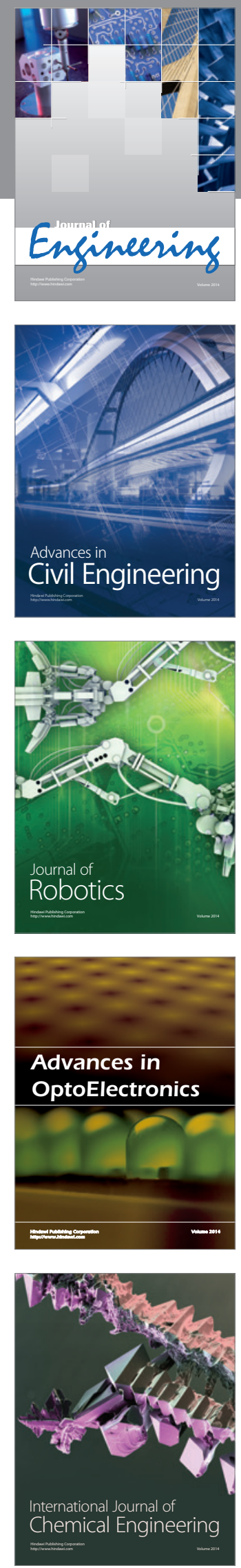

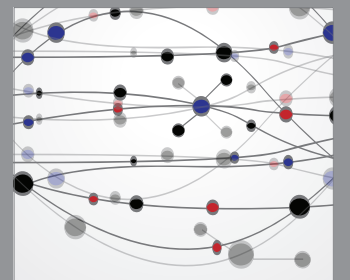

The Scientific World Journal
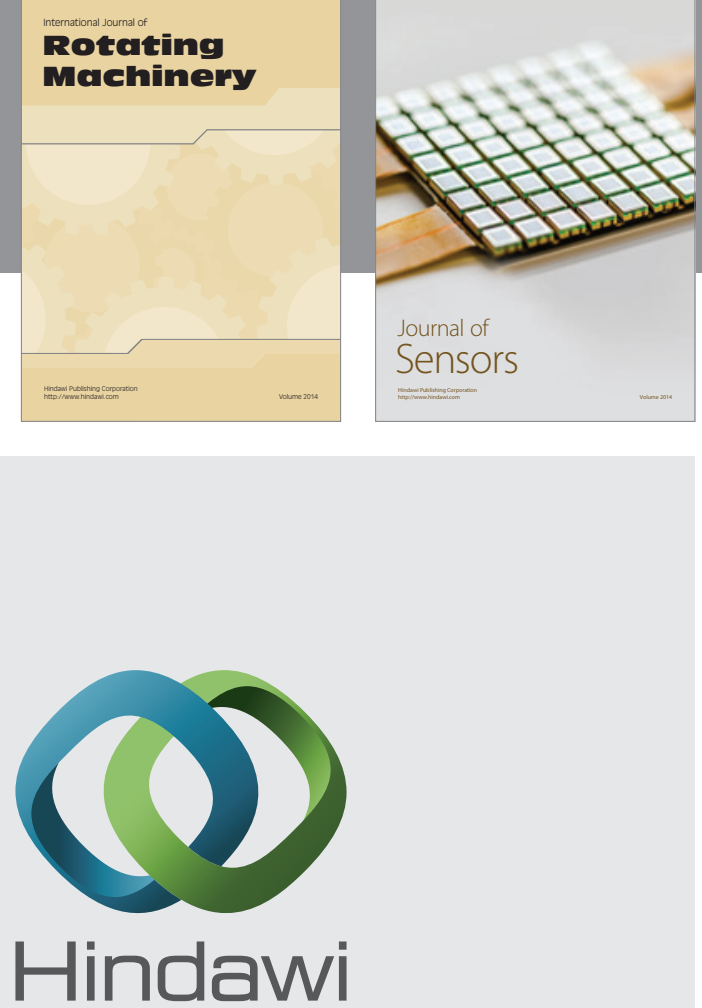

Submit your manuscripts at http://www.hindawi.com
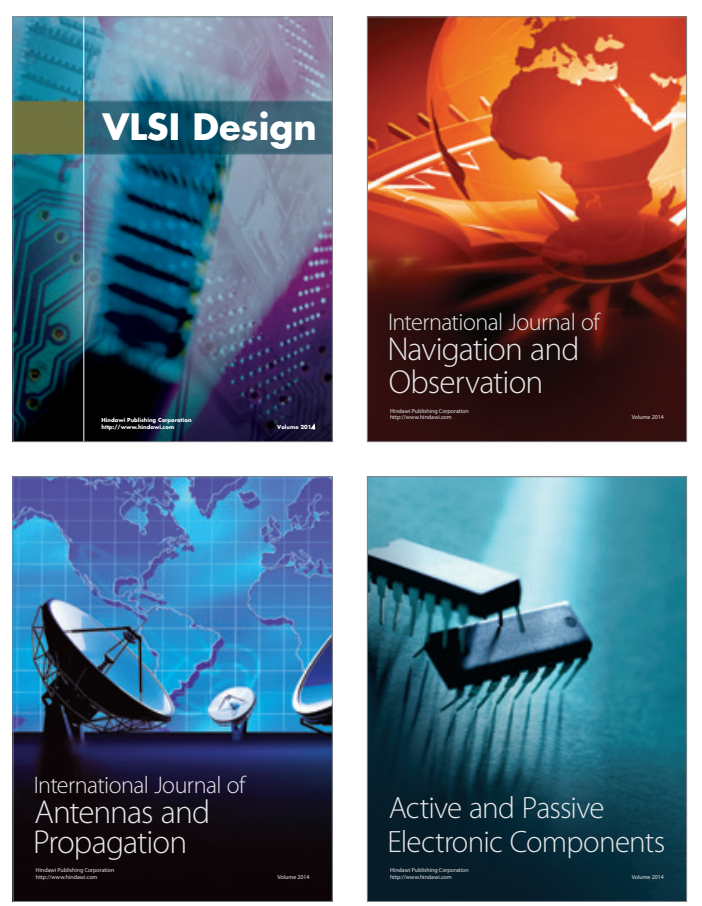
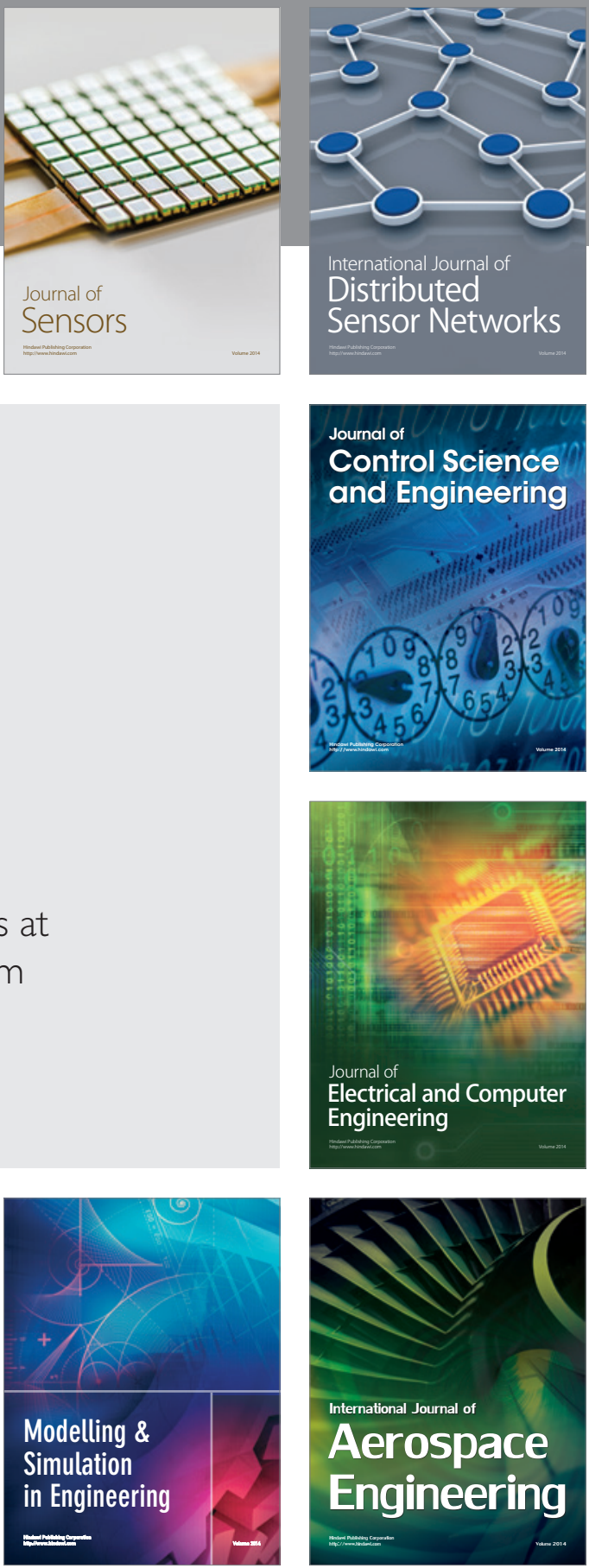

Journal of

Control Science

and Engineering
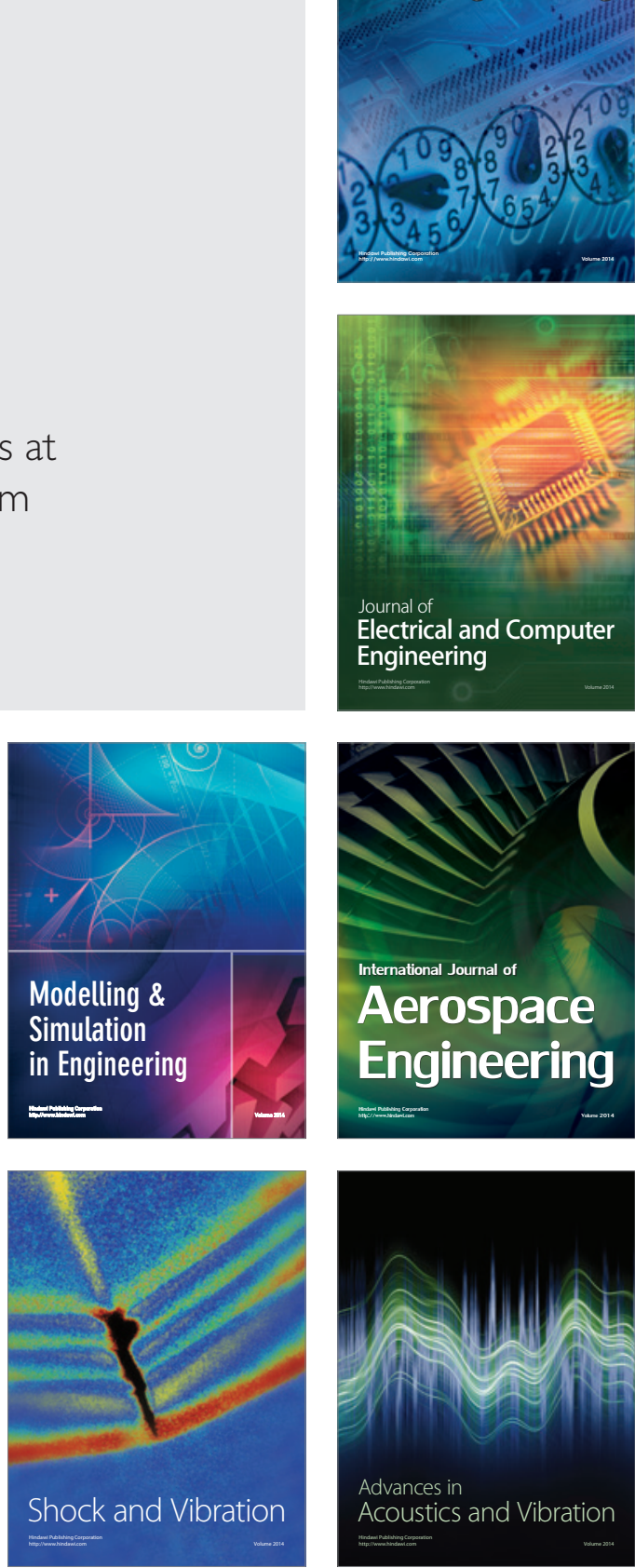